Chinese Journal of Organic Chemistry

REVIEW

\title{
$\mathrm{AlCl}_{3}$ 促进的有机反应研究进展
}

\author{
袁康宁 ${ }^{a}$ 赵玉英 ${ }^{b}$ 常宏宏 ${ }^{a}$ 田 俊 ${ }^{a}$ 高文超*, $a$ \\ $\left({ }^{a}\right.$ 太原理工大学生物医学工程学院 太原 030024) \\ $\left({ }^{b}\right.$ 太原科技大学化学与生物工程学院 太原 030021)
}

\begin{abstract}
摘要 三氯化铝 $\left(\mathrm{AlCl}_{3}\right)$ 作为硬路易斯酸的典型代表, 其促进的有机转化近些年来越来越受到人们的关注. 总结了近 10 年来通过三氯化铝对含卤素、氧、氮、硫原子化合物及 $\pi$ 键的活化完成的多种有机转化, 并对所涉及的相关反应及活 化机制进行了系统介绍，同时对三氯化铝新的应用领域进行了展望.
\end{abstract}

关键词 三氯化铝; 活化作用; 活化机制; 有机催化

\section{Recent Advances in $\mathrm{AlCl}_{3}$-Promoted Organic Reactions}

\author{
Yuan, Kangning $^{a} \quad$ Zhao, Yuying $^{b} \quad$ Chang, Honghong ${ }^{a} \quad{\text { Tian, } \text { Jun }^{a} \quad \text { Gao, Wenchao }}^{*, a}$ \\ ( ${ }^{a}$ College of Biomedical Engineering, Taiyuan University of Technology, Taiyuan 030024) \\ $\left({ }^{b}\right.$ School of Chemical and Biological Engineering, Taiyuan University of Science and Technology, Taiyuan 030021)
}

\begin{abstract}
As a representative hard Lewis acid, aluminum trichloride $\left(\mathrm{AlCl}_{3}\right)$ has attracted more and more attention in the past decades. The reactions promoted via the activation of halogens, oxygen, nitrogen, sulfur compounds and $\pi$-bonds with $\mathrm{AlCl}_{3}$ are systematically reviewed, and some recent progress in last ten years is updated as well. Moreover, the new application fields of $\mathrm{AlCl}_{3}$ are prospected.

Keywords aluminum trichloride; activation; activation mechanism; organic catalysis
\end{abstract}

铝在自然界中主要以铝硅酸盐矿石、铝土矿以及冰 晶石等化合态形式存在, 元素丰度在地壳中占第五位 ${ }^{[1]}$. 19 世纪 20 年代, 人们才首次发现用钾录齐还原无水卤 化铝可以制备单质铝. 然而当时由于价格非常昂贵，只 有欧洲的贵族才用得起，所以被称为“银色的金子”. 直 到 19 世纪后期发明了电解法生产铝, 才使铝的价格大 降, 使铝得以广泛应用 ${ }^{[2]}$.

在合成化学中, 常用的含铝化合物包括四氢铝锂 $\left(\mathrm{LiAlH}_{4}\right)$ 、二异丙基铝氢( DIBAL-H)、三乙基铝 $\left(\mathrm{Et}_{3} \mathrm{Al}\right)$ 和氧化铝 $\left(\mathrm{Al}_{2} \mathrm{O}_{3}\right)$ 等, 是合成化学领域重要的催化剂、还 原剂以及吸附剂. 三氯化铝 $\left(\mathrm{AlCl}_{3}\right)$ 是铝的氯化物, 为无 色透明晶体或白色而微带浅黄色的结晶性粉末, 在高温 可形成平面三角形的 $\mathrm{AlCl}_{3}$ 单体; 而在溶液和低温气相 中主要以含有氯桥的 $\mathrm{Al}_{2} \mathrm{Cl}_{6}$ 二聚体存在 (Scheme 1) ${ }^{[3]}$. 从分子轨道理论来讲, 每个铝原子通过一个 $3 \mathrm{~s}$ 轨道和

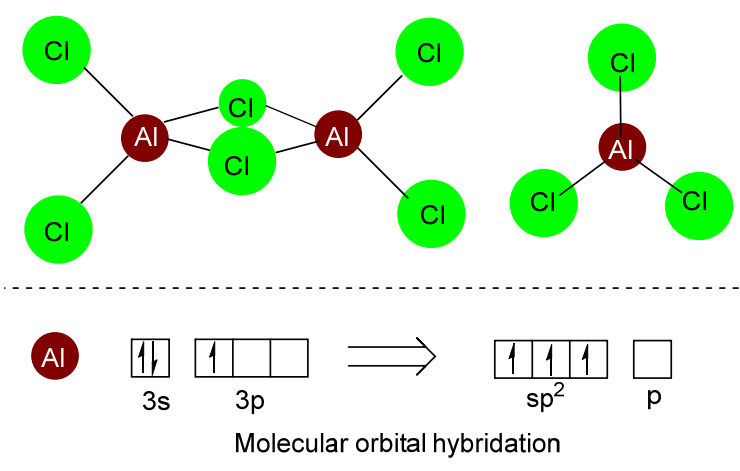

图式 $1 \mathrm{Al}_{2} \mathrm{Cl}_{6}$ 与 $\mathrm{AlCl}_{3}$ 的结构及 $\mathrm{Al}$ 与 $\mathrm{AlCl}_{3}$ 的杂化方式 Scheme 1 Structures of $\mathrm{Al}_{2} \mathrm{Cl}_{6}$ and $\mathrm{AlCl}_{3}$ and the molecular orbital hybridization of $\mathrm{Al}$ and $\mathrm{AlCl}_{3}$

两个 $3 p$ 轨道形成不等性的 $\mathrm{sp}^{2}$ 杂化, 并分别与氯原子形 成 $\sigma$ 键 $^{[3]}$, 整个分子在单体时几乎成平面结构. 作为一

\footnotetext{
* Corresponding author. E-mail: gaowenchao@tyut.edu.cn

Received April 26, 2020; revised May 16, 2020; published online May 29, 2020.

Project supported by the National Natural Science Foundation of China (No. 21901179), the Key Research and Development Program of Shanxi Province (International Cooperation) (No. 201803D421093), the Natural Science Foundation of Shanxi Province (No. 201901D211052) and the Research Project Supported by Shanxi Scholarship Council of China (Nos. HGKY2019029, 2020-053).

国家自然科学基金(No. 21901179)、山西省重点研发计划(国际合作)(No. 201803D421093)、山西省自然科学基金(No. 201901D211052)以及山西省留学 回国人员科研教研(Nos. HGKY2019029, 2020-053)资助项目.
} 
种十分重要的无机试剂, 它被广泛地用在石油工业、染 料工业、食品添加剂和化学合成等领域.

路易斯酸碱理论认为凡是可以接受外来电子对的 分子、基团或离子都被称作路易斯酸(Lewis Acid, LA), 分子内通常具有可以用来接收外来分子电子对的空轨 道. 通过 $\mathrm{AlCl}_{3}$ 铝原子的轨道模型, 可看出其未参与杂 化的 $\mathrm{p}$ 轨道具有接收电子对的能力(Scheme 1), 因此 $\mathrm{AlCl}_{3}$ 属于典型的路易斯酸. Pearson 等 $^{[4]}$ 又根据变形能 力的相对大小将路易斯酸分为软酸和硬酸. 硬酸对外层 电子吸引力强, 其结构特点是正电荷高、体积小、变形 性低, $\mathrm{AlCl}_{3}$ 分子恰恰又具有这些特点. 因此, $\mathrm{AlCl}_{3}$ 属于 硬酸, 更容易接受来自硬碱(如羰基氧、醚类、含氮有机 碱等)或卤素原子的孤对电子, 增强官能团的极化作用 或者促进 $\mathrm{C}-\mathrm{X}$ 键断裂, 发生如傅克(Friedel-Crafts)反 应、狄尔斯-阿尔德(Diels-Alder)及迈克尔加成(Michael addition)反应等. 此外, 三氯化铝未成键的空轨道, 也 可与 $\pi$ 键形成配位键, 从而体现出活化烯烃和炔烃等 $\pi$ 路易斯酸的性质 ${ }^{[5]}$. 三氯化铝作为一种“古老的催化剂”, 应用于有机反应已有百年历史, 直到今天依然有新的反 应被发现. 自 2003 年赵颖等 ${ }^{[6]}$ 对三氯化铝催化的有机反 应总结之后, 至今未有相关的综述性文章报道. 本文综 述了近 10 年利用三氯化铝为催化剂或促进剂的若干新 型的有机转化, 并对三氯化铝的活化机制进行了详细的 讨论.

\section{1 对卤素的活化作用}

\section{$1.1 \mathrm{AlCl}_{3}$ 促进的傅克反应}

1877 年, Friedel 和 Crafts 用 $\mathrm{AlCl}_{3}$ 与 1-氯戊烷和苯 的混合液反应, 得到了戊苯. 这是历史第一个傅克反应. 在此之后，他们还用其他金属卤化物催化该反应，并由 此提出傅克烷基化和傅克酰基化反应的反应进程 (Scheme 2): 卤代烃或酰氯在 $\mathrm{AlCl}_{3}$ 作用下产生烷基正 离子或者酰基正离子, 作为亲核试剂进攻芳环, 最后失 去一个质子生成烷基芳烃或芳香酮, $\mathrm{AlCl}_{3}$ 再生继续下一 个催化循环 ${ }^{[7]}$. 常用的烷基化试剂有卤代烃、烯烃和醇 等. 常用的酰基化试剂有酰氯和羧酸酐等. 一直到今天, $\mathrm{AlCl}_{3}$ 仍然是傅克反应的重要催化剂之一. 近些年来, 除了一些的基本的芳基酮或者取代芳烃的合成之外，在 $\mathrm{AlCl}_{3}$ 的催化作用下, 还可以合成多种杂环及不饱和烯 酮等结构.

\section{$1.2 \mathrm{AlCl}_{3}$ 促进的傅克烷基化反应}

2013 年, Chong 课题组 ${ }^{[8]}$ 通过 $\mathrm{AlCl}_{3}$ 促进芳基 $\beta$-卤代 胺分子内傅克烷基化合成了的 4-取代四氢异喹啉 2 具有 较高的对映选择性, 收率最高可达 $95 \%$ (Scheme 3). 值 得注意的是，芳基 $\beta$-卤代胺并不仅限于芳基 $\beta$-溴代胺,

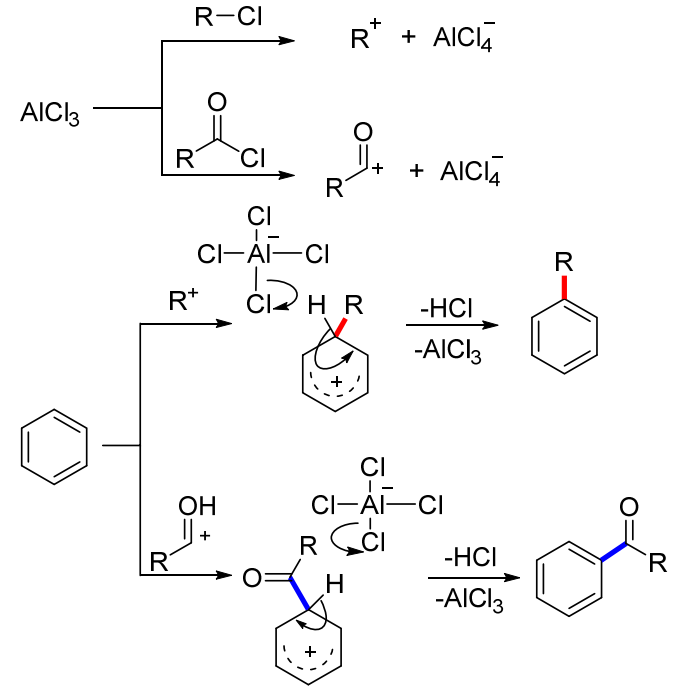

图式 $2 \mathrm{AlCl}_{3}$ 促进的傅克烷基化反应及酰基化反应 Scheme $2 \mathrm{AlCl}_{3}$ promoted Friedel-Crafts alkylation and acylation

芳基 $\beta$-氯代胺及芳基 $\beta$-碘代胺同样可进行该反应. 产物 的单晶结构表明该分子内反应的手性中心的构型得到 了保持. 该反应的区域选择性和立体专一性主要是由于 中间体氮杂环丙烷离子的产生：首先在 $\mathrm{AlCl}_{3}$ 催化下， 芳基 $\beta$-卤代胺 $1 \mathrm{a}$ 通过分子内 $\mathrm{S}_{\mathrm{N}} 2$ 途径生成氮杂环丙烷 离子 3, 随后氮杂环丙烷离子 $\mathbf{3}$ 中 $\mathrm{N}-\mathrm{C}$ 键断裂形成碳 正离子 4. 通过 $\mathrm{N}$ 端芳环进攻碳正离子 4 完成分子内傅 克烷基化反应得到碳正离子中间体 $\mathbf{5}$, 并最终消除质

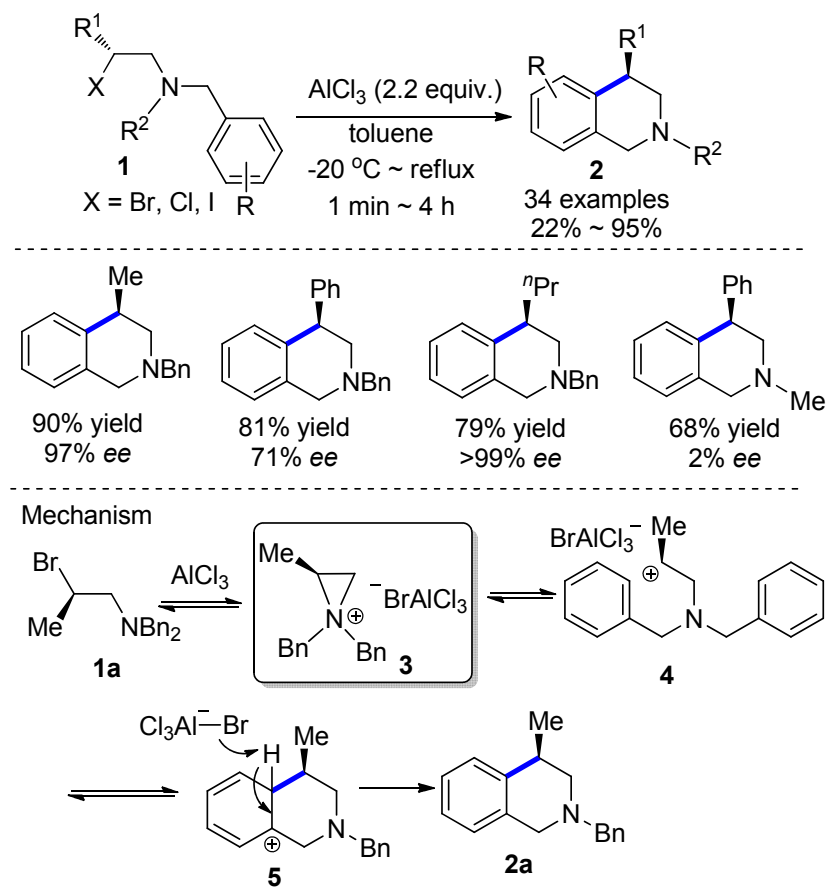

图式 $3 \mathrm{AlCl}_{3}$ 促进的 4-取代四氢异喹啉的合成 Scheme 3 Synthesis of 4-substituted tetrahydroisoquinolines promoted by $\mathrm{AlCl}_{3}$ 
子形成 4-取代四氢异喹啉.

\section{$1.3 \mathrm{AlCl}_{3}$ 促进的傅克酰基化反应}

$\alpha, \beta$-不饱和酮是用于迈克尔加成 ${ }^{[9]}$ 和环氧化反应 ${ }^{[10]}$ 等的重要模块. 传统构建 $\alpha, \beta$-不饱和酮的方法限制较多, 通过 $\alpha$-烯烃直接酰化是一个理想的途径. 傅克反应不仅 适用于芳香族化合物，烯烃也能利用该反应引入酰基， 目前已有一些关于烯类化合物与酸酐 ${ }^{[11]}$ 、酰氯 ${ }^{[12]}$ 和其他 酰化试剂 ${ }^{[13]}$ 进行酰化反应的报道. 2019 年, Tanaka 课题 组 ${ }^{[14]}$ 通过 $\mathrm{AlCl}_{3}$ 和 2,6-二溴吡啶的联用, 成功地实现了 烯烃与酰氯的傅克酰基化反应(Scheme 4). 值得注意的 是, 各种烯烃在 2,6-二溴吡啶的存在下成功发生酰化而 不发生聚合, 普适性良好, 收率最高可达定量. 通过机 理验证实验，他们认为: 酰氯 7 在 $\mathrm{AlCl}_{3}$ 作用下生成酰基 正离子 9 , 随后烯烃 6 与酰基正离子 9 反应得到的碳正 离子中间体 10, 最后经过 2,6-二溴吡啶提取质子生成烯 酮 8.
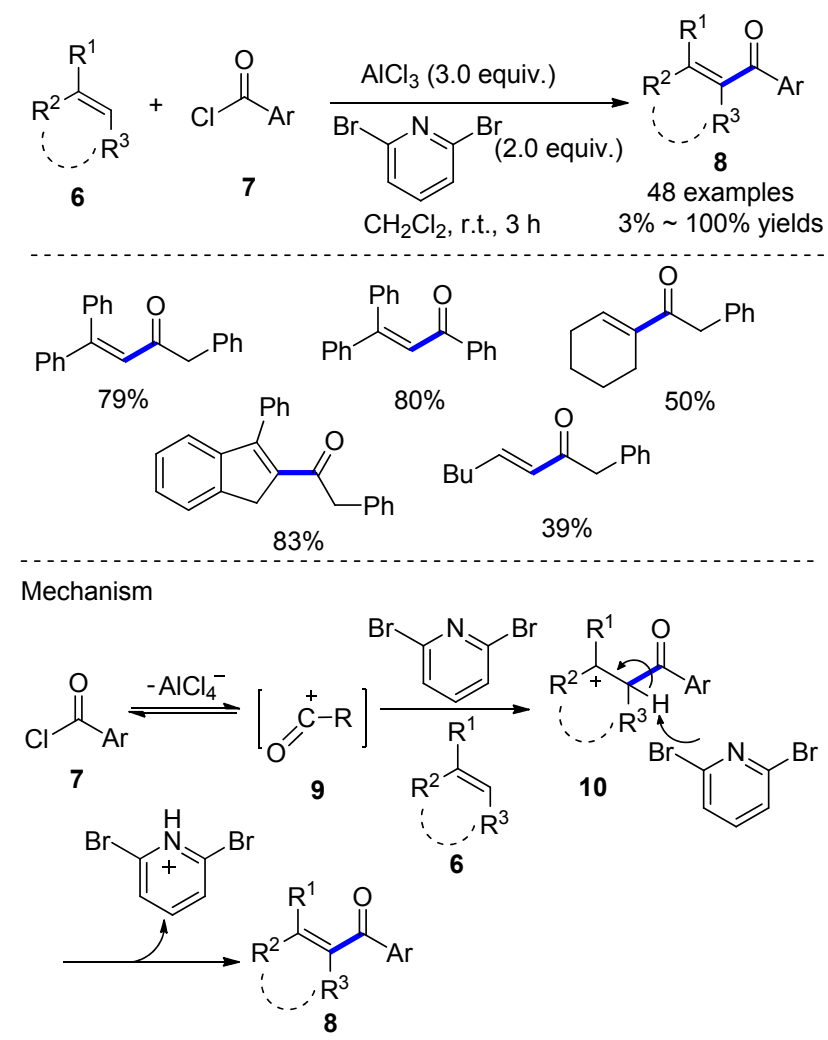

图式 $4 \mathrm{AlCl}_{3}$ 促进的 $\alpha, \beta$-不饱和烯酮的合成

Scheme 4 Synthesis of $\alpha, \beta$-unsaturated enones promoted by $\mathrm{AlCl}_{3}$

在传统的间歇反应(batch reaction)中, $\mathrm{AlCl}_{3}$ 通过活 化酰氯促进炔烃的傅克酰基化反应容易生成立体异构 $\beta$-氯乙烯基酮的混合物, $E$ 构型在反应体系中容易向 $Z$ 构型转化(Scheme 5a). $E / Z$ 异构化的主要原因是炔烃, 三氯化铝以及产物烯酮形成的反应中间体通过分子内
的加成反应形成 $Z$ 式产物 13 (Scheme 5b). 2019 年, Kim 课题组 ${ }^{[15]}$ 使用流动化学的方法, 可以使生成 $(E)-\beta$-氯代 乙烯基酮及时从反应体系中分离，从而减少流动系统中 其他反应组分的相互作用，达到高选择性合成 $(E)-\beta$-氯 代乙烯基酮 14 的目的. 具体操作是将 $\mathrm{AlCl}_{3}$ 与酰氯在流 动体系中的一条通道混合，炔烃从另一条通道中加入 (Scheme $5 \mathrm{c}$ ), 产物与酰氯及 $\mathrm{AlCl}_{3}$ 形成复合物的时间被 大大缩短，从而提高了 $E$ 式的选择性. 总体来看，与间 歇反应相比, 流动化学方法为 $(E)-\beta$-氯乙烯基酮的合成 提供了一条快速、高产、立体选择性的合成路线.
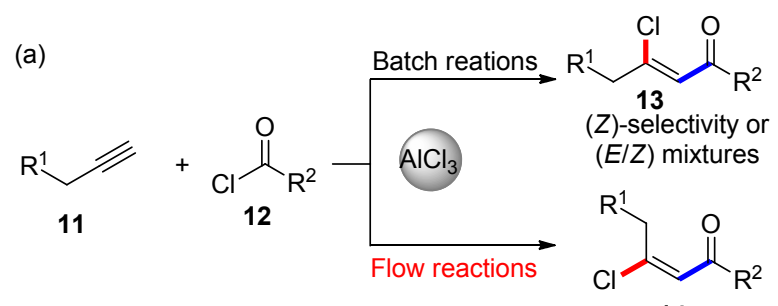

14

(E)-selectivity 23 examples $60 \% \sim 84 \%$

(b)
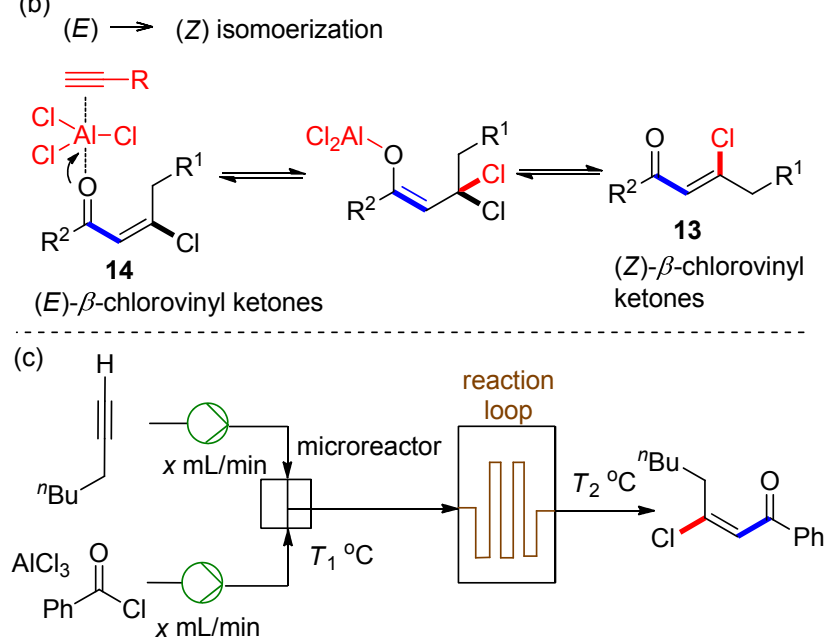

图式 $5 \mathrm{AlCl}_{3}$ 促进的 $(E)-\beta$-氯代乙烯基酮的合成 Scheme 5 Synthesis of $(E)-\beta$-chlorovinyl ketones promoted by $\mathrm{AlCl}_{3}$

\section{2 对氧的活化作用}

\section{$2.1 \mathrm{AlCl}_{3}$ 促进的加成环合反应}

迈克尔加成(Michael addition)是指是亲电的共轭体 系与亲核的负碳离子进行的共轭加成反应，主要用于增 长碳链, 是构筑碳一碳键的最常用方法之一. 2014 年, 贾 学顺课题组 ${ }^{[16]}$ 报道了以 1,2 -二氯乙烷为溶剂, 吲哚啉酮 与乙基-2,3-丁二烯酸酯在 $\mathrm{AlCl}_{3}$ 促进下发生区域选择性 迈克尔加成合成双取代吲哚啉酮 17 与螺吲哚啉酮环己 酮 18 (Scheme 6). 实验结果表明，反应在很大程度上依 
赖于吲哚啉酮碳碳双键连接的官能团 $\mathrm{R}^{2}$ 种类, 当双键 相连的为酯基时，亲核加成从乙烯基的环外位点开始 (Scheme 6, site 1): 通过 $\mathrm{AlCl}_{3}$ 与羰基配位活化双键, 使 吲哚啉酮 15a 与乙基-2,3-丁二烯酸酯(16a)发生迈克尔 加成得到碳正离子中间体 19; 同时, $\mathrm{AlCl}_{3}$ 作为氯化试剂 使氯离子捕获碳正离子中间体 19 得到中间体 20, 随后 在 $\mathrm{AlCl}_{2}{ }^{+}$的作用下乙氧基作为离去基完成 Dieckmann 型 环化得到螺吲哚啉酮环己酮 18a. 相比之下, 当与双键 相连的为羰基时, 亲核位点转移到双键的环内结合点 (Scheme 6, site 2), 只发生加成反应和氯化反应.
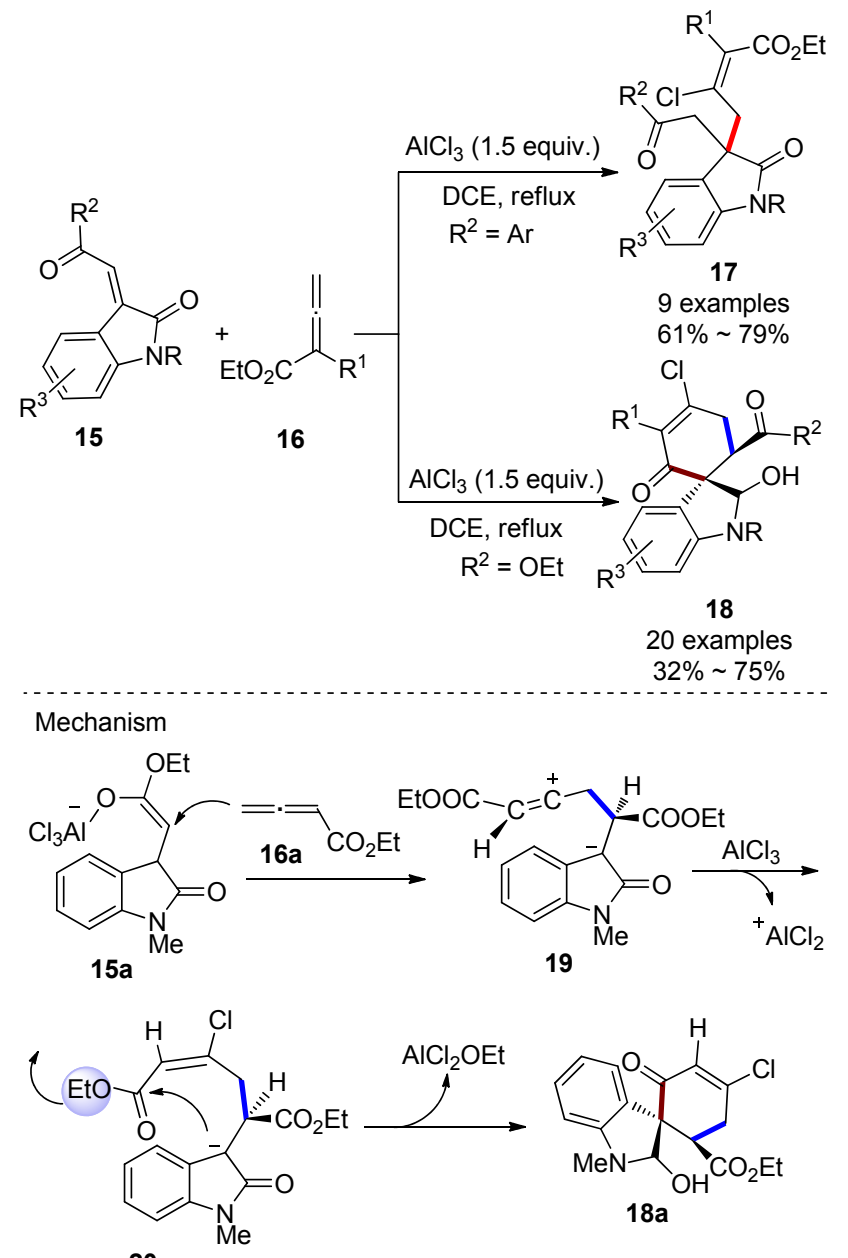

20

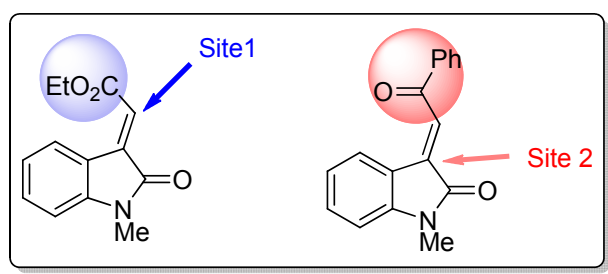

图式 $6 \mathrm{AlCl}_{3}$ 促进的螺吲哚琳酮环己酮的合成

Scheme 6 Synthesis of spirocyclic oxindole-dihydropyrans promoted by $\mathrm{AlCl}_{3}$

\section{$2.2 \mathrm{AlCl}_{3}$ 催化的缩合环合反应}

Pechmann 缩合反应是目前应用最广泛的通过酚类
和 $\beta$-酮类化合物合成香豆素类衍生物的方法. 但 $\beta$-酮类 化合物多限于使用 $\beta$-酮酯，如乙酰乙酸乙酯或乙酰乙酸 甲酯等. 2013 年, Singh 课题组 ${ }^{[17]}$ 报道了在无溶剂条件 下, $\mathrm{AlCl}_{3}$ 催化下酚类和 $\beta$-羰基二硫酯 22 进行 Pechmann 缩合反应合成 $2 H$-苯并吡喃-2-硫酮 23 (Scheme 7), 收率 最高可达 $85 \%$. 并提出了一种可能的机理: 酚差基的孤 对电子进攻二硫酯 $\mathbf{2 1}$ 的硫羰基碳，消除甲硫醇，得到中 间体 24, 随后通过 $\pi$-电子对活性羰基碳的亲电进攻来 完成环闭合，进一步由中间体 25 消除一分子水得到 $2 H$ 苯并吡喃-2-硫酮 23. 值得一提的是, 酚类结构中至少含 有两个供电子的酚羟基才能完成该转化.
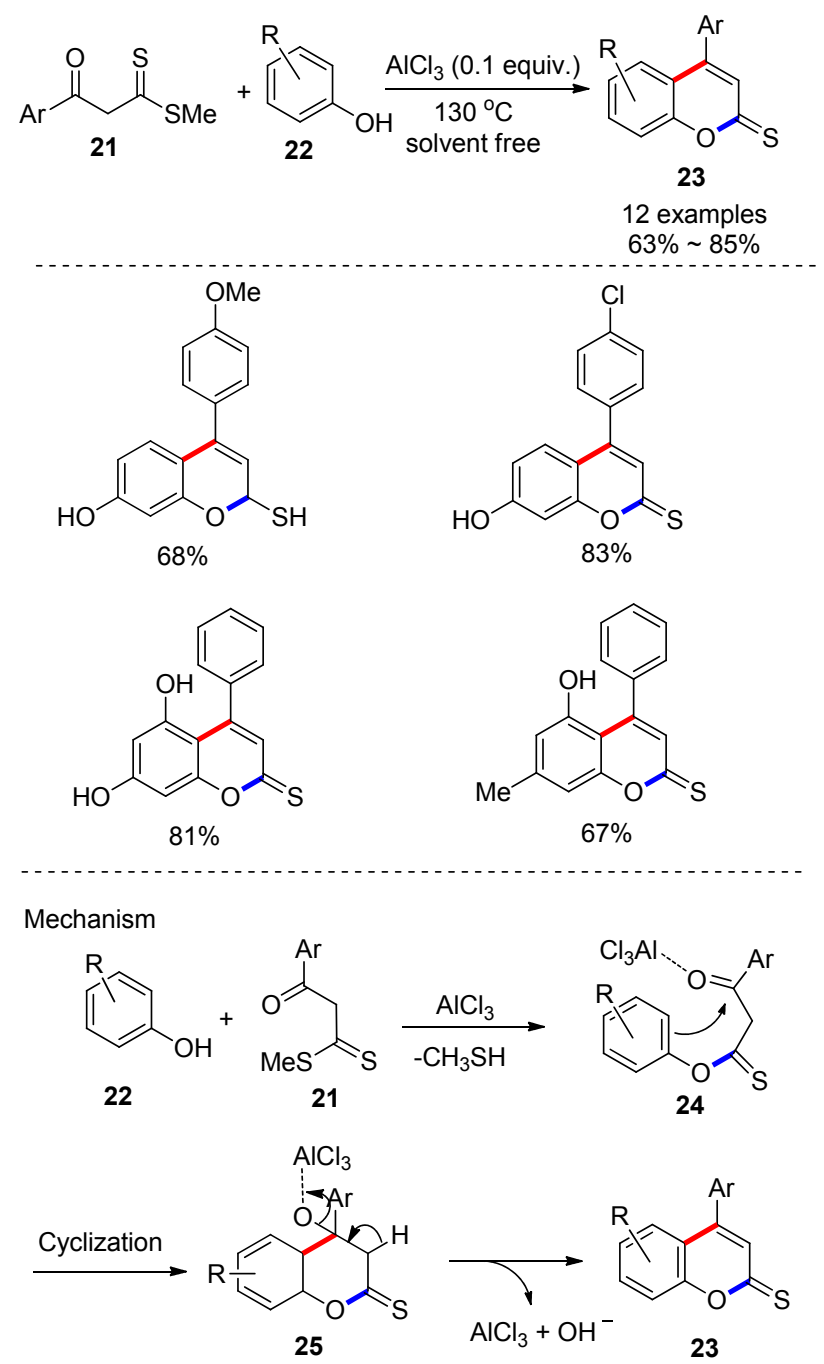

图式 $7 \mathrm{AlCl}_{3}$ 催化的 $2 \mathrm{H}$-苯并吡喃-2-硫酮的合成 Scheme $7 \mathrm{AlCl}_{3}$-catalyzed synthesis of $2 \mathrm{H}$-chromene-2-thiones

\section{$2.3 \mathrm{AlCl}_{3}$ 催化的脱水环合反应}

2017 年, 樊晓辉课题组 ${ }^{[18]}$ 报道了通过 $\mathrm{AlCl}_{3}$ 催化肉 桂醛或芳基苯甲醛与对甲苯磺酰胺环化生成狮胺 28 和 芴胺 29 衍生物的方法(Scheme 8). 优化后的反应条件与 多种肉桂醛和芳基苯甲醛具有良好的底物相容性, 产率 
中等至良好. 同时他们通过一系列控制性实验对反应机 理进行了相应的研究: $\mathrm{AlCl}_{3}$ 催化肉桂醛和对甲苯磺酰 胺原位生成亚胺离子 $30 ; 30$ 可以通过键旋转异构化得到 其 $Z$ 异构体 31; 随后, 31 经过分子内氮杂傅克反应或 $4 \pi$ 电环化过程, 得到目标产物. 值得一提的是, 通过该方 法制备的狮和芴衍生物可以一步合成茚酮和芴酮.

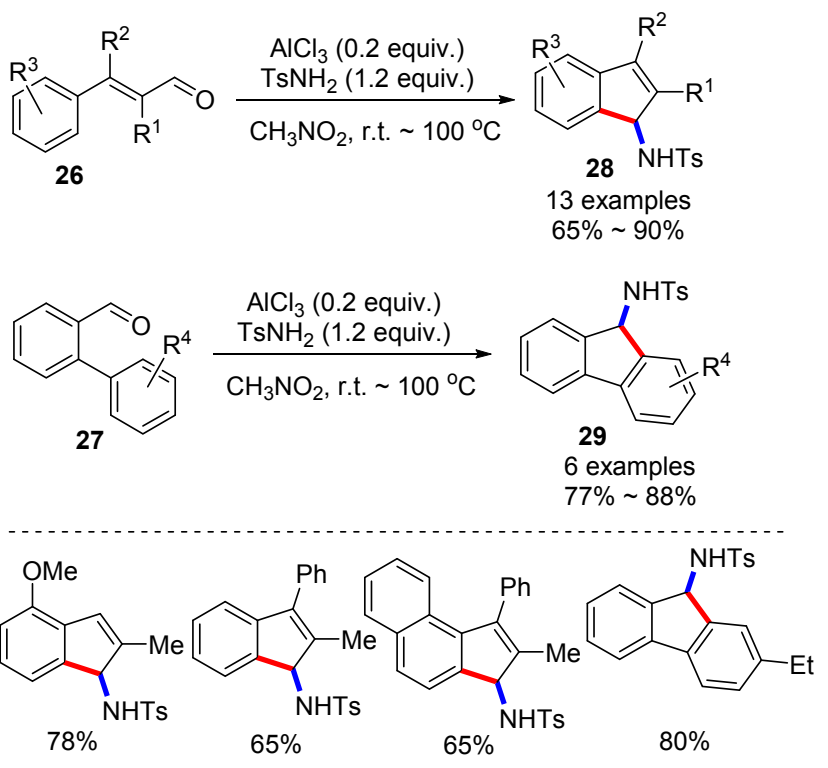

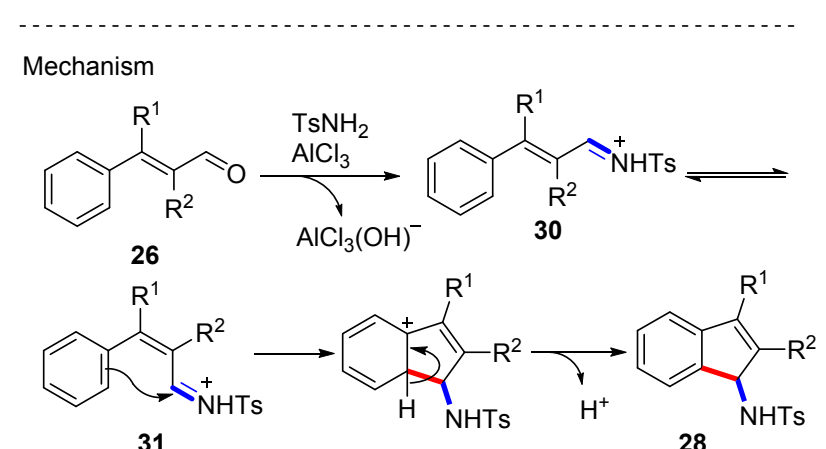

图式 $8 \mathrm{AlCl}_{3}$ 催化的狮胺和芴胺衍生物的合成 Scheme $8 \mathrm{AlCl}_{3}$-catalyzed synthesis of fluorenyl amine and indenyl amine derivatives

2018 年, 佟硕课题组 ${ }^{[19]}$ 报道了利用 $\mathrm{AlCl}_{3}$ 与 $\mathrm{Sc}(\mathrm{OTf})_{3}$ 催化相同的烯酰胺选择性地合成多取代邻氨基 醇和吡咯衍生物 33 (Scheme 9). 在 $\mathrm{AlCl}_{3}$ 和 $4 \AA$ 分子篎的 催化作用下, 烯酰胺经分子内环化得到多取代吡咯, 产 率高, 普适性好. 通过制备多取代吡咯的克级反应进一 步证明了该方法的合成应用价值. 他们认为: $\mathrm{AlCl}_{3}$ 活化 醛基得到中间体 34, 通过与分子内烯烃的亲核加成得 到的中间体 35 经过异构化得到中间体 36, 最后通过脱 水芳构化提供产物 33. 该研究表明叔烯酰胺类化合物 在有机合成中的重要性和功能性: 通过催化剂控制可以 表现出多样的反应活性和不同的反应途径.
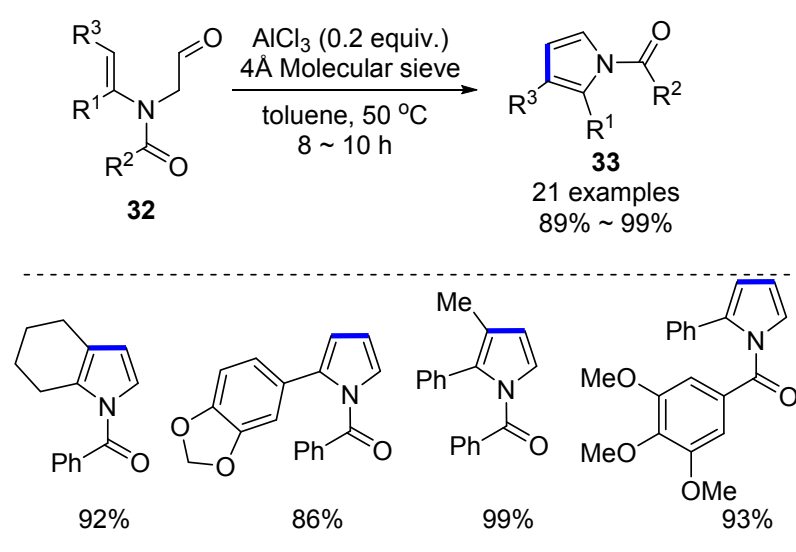

Mechanism
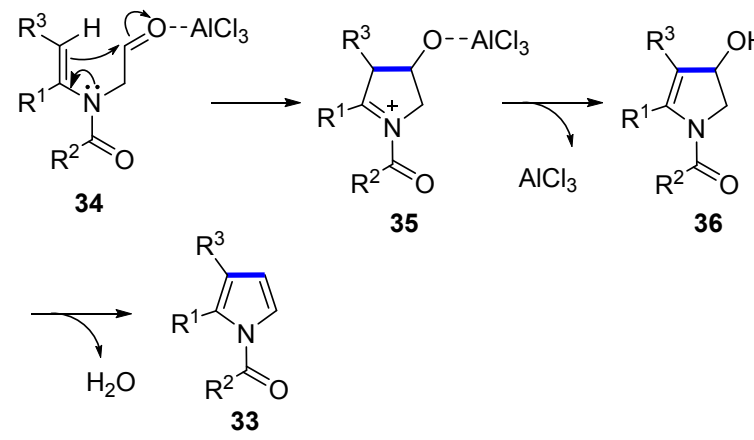

36

图式 $9 \mathrm{AlCl}_{3}$ 催化的 $N$-酰基吡咯的合成

Scheme $9 \mathrm{AlCl}_{3}$-catalyzed synthesis of $\mathrm{N}$-acyl-pyrroles

\section{$2.4 \mathrm{AlCl}_{3}$ 催化的亲电环合反应}

喹啉酮及其衍生物是许多天然产物中最重要的杂 环化合物之一，也是药物化学中具有药理活性的分子之 一 ${ }^{[20]}$. 在有机分子或杂环中引入硫醚结构可显著增强 其活性并改变其物理和药理学性质 ${ }^{[21]}$. 在喹啉酮结构

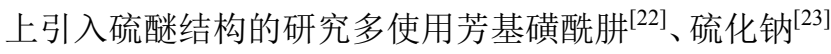
及硫醇等硫源. 2017 年, 我们课题组 ${ }^{[24]}$ 使用 $N$-硫代丁二 酰亚胺为硫源, 通过 $\mathrm{AlCl}_{3}$ 催化 $N$-芳基丙烯酰胺分子内 环化反应合成 3-硫代喹啉酮 39 及 3-硫代氮杂螺 [4,5]烯 酮 40 (Scheme 10). 产物的选择性主要通过底物酰胺芳 环上的取代基进行调控. 通过相关的控制实验, 提出了 邻位和原位环化的机理: 通过 $\mathrm{AlCl}_{3}$ 对 $N$-硫代丁二酰亚 胺 37 的活化作用生成硫正离子 41, $N$-芳基丙烯酰胺 38 的参键容易受到硫正离子 41 进攻, 由此得到的硫鎓离 子 42 通过分子内邻位亲核环化与脱质子作用得到 3-硫 代喹啉酮类衍生物 39; 如果氟位于酰胺的对位，容易受 到外部亲核试剂如 $\mathrm{H}_{2} \mathrm{O}$ 或 $\mathrm{MeOH}$ 的进攻, 进一步会引起 分子内 ipso-环化得到中间体 $\mathbf{4 3}$, 通过脱质子、脱氟与亲 核置换脱去中间体 43 中的甲基得到 3-硫代氮杂螺 [4,5] 烯酩 40. 值得一提的是，该反应可通过进一步衍生制备 苯并噻吩 $[3,2-b]$ 喹啉和苯并噻吩 [2,3-c]喹啉酮这两种具 有生物活性的杂环化合物. 


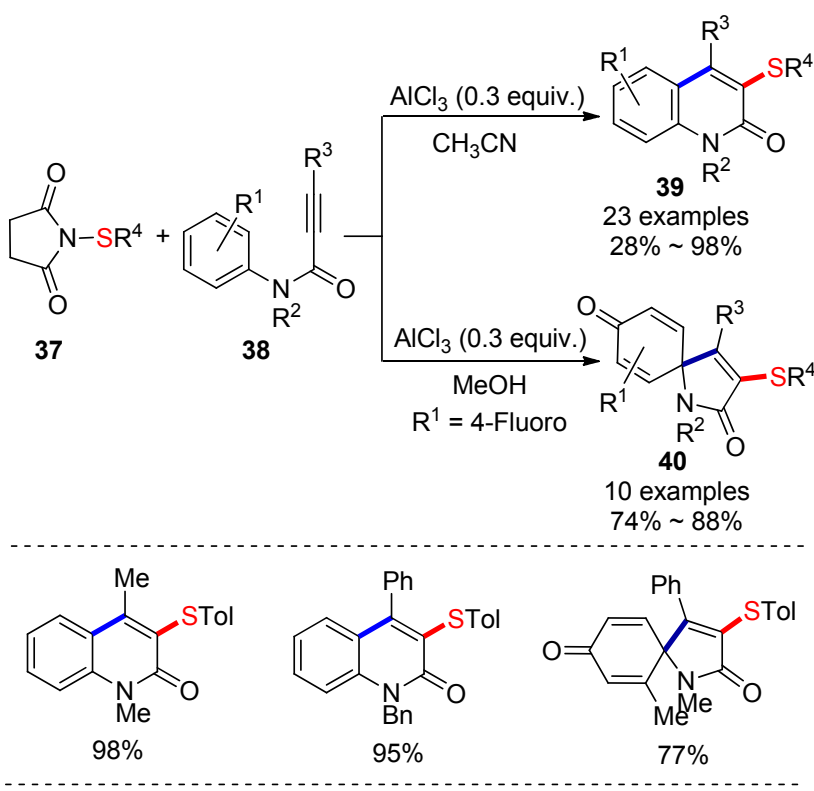

Mechanism<smiles></smiles>

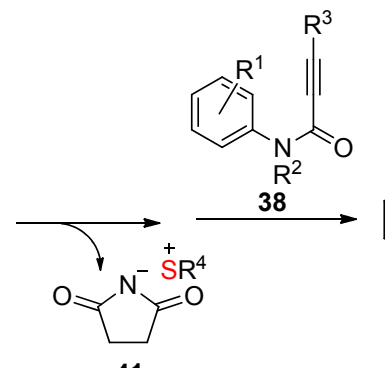<smiles>[R2]Nc1ccccc1NC(=O)C1=C([R])[R7]1=[R]</smiles>

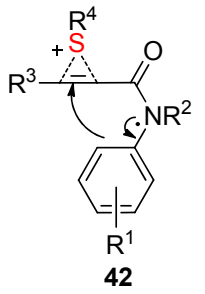

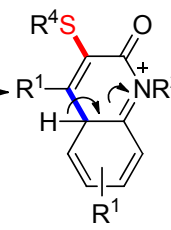

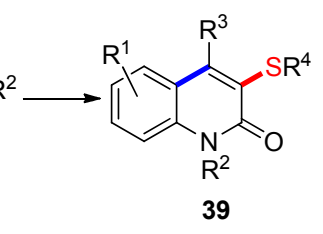

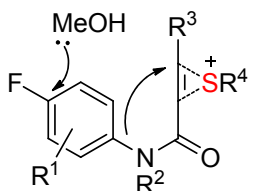

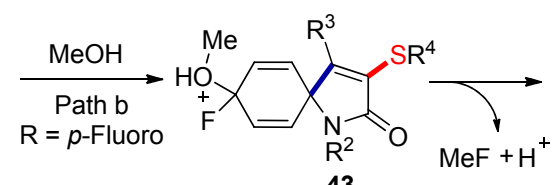<smiles>[R]C1=C([R])C([R])(/C=C\C(=O)C=[R])NC1=O</smiles>

40

图式 $10 \mathrm{AlCl}_{3}$ 催化的 3-硫代喹啉酮和 3-硫代氮杂螺 [4,5]烯酮 的合成

Scheme $10 \mathrm{AlCl}_{3}$-catalyzed synthesis of 3-sulfenyl quinolin2-ones and azaspiro[4,5]trienones

2019 年, 我们课题组 ${ }^{[25]}$ 发现使用 $\mathrm{AlCl}_{3}$ 促进 $N$-芳基 硫代丁二酰亚胺或二烷基二硫可以完成由 2-炔基-1-甲 氧基酮肜到 4-硫代异噁唑 47 的转化(Scheme 11). 通过 相关的控制实验，我们认为该反应同样是通过硫正离子

途径进行的: 通过 $\mathrm{AlCl}_{3}$ 与 $N$-芳基硫代丁二酰亚胺 45 或二烷基二硫 46 作用生成硫正离子 48 , 硫正离子 48 进 攻参键得到硫鎓离子 49 , 随后通过分子内环化与去甲 基化作用得到 4-硫代异噁唑 47. 这样, 我们就可以通过 控制反应条件得到两种不同的硫代异噁唑：使用 $N$-芳 基硫代丁二酰亚胺可以得到 4-芳基硫代异噁唑，而使用 二烷基二硫时可以得到 4-烷基硫代异噁唑. 此外, 借助 $\mathrm{AlCl}_{3}$ 对亲电硫试剂的活化作用，炔酮腙类底物 $\mathbf{5 0}$ 可以 以较好的收率得到 4-硫代吡唑类结构 51, 该方法进一 步地应用于抗炎药物塞来昔布的衍生和修饰中(Scheme $11 \mathrm{c})^{[26]}$.

(a)
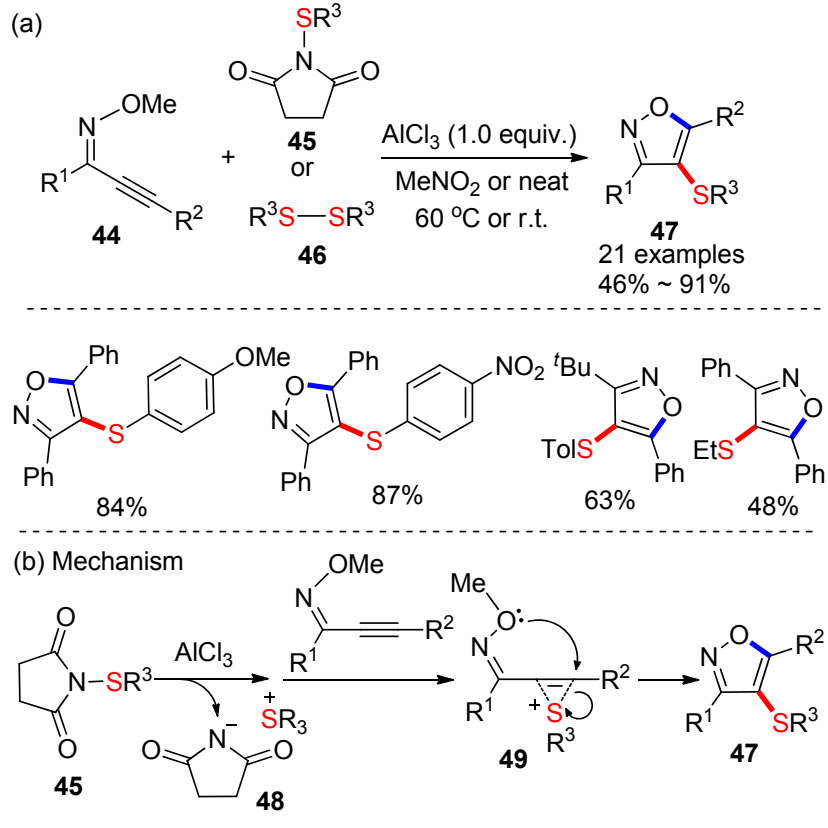

(c)
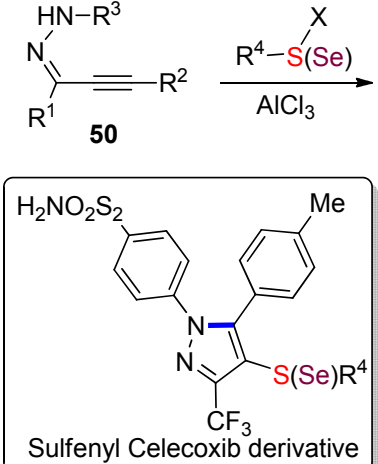

图式 $11 \mathrm{AlCl}_{3}$ 促进的 4-硫代异噁唑/吡唑的合成 Scheme 11 Synthesis of 4-sulfenyl isoxazoles/pyrazoles promoted by $\mathrm{AlCl}_{3}$

\section{$2.5 \mathrm{AlCl}_{3}$ 促进的取代反应}

2013 年, 王忠卫课题组 ${ }^{[27]}$ 报道了 $\mathrm{AlCl}_{3}$ 促进 $2 \mathrm{H}$-苯 并吡喃与各种烯基硅醚之间的亲核取代反应，合成了一 系列 4-取代-2-三氟甲基-3-乙氧甲酰基-4H-苯并吡喃 54 
(Scheme 12). 羟基离去基团位于 $2 \mathrm{H}$-苯并二氢吡喃的 2 位, 而取代位点位于 4 位. 他们认为这些反应仅发生在 $2 H$-苯并吡喃的 4 位可能是由于三氟甲基空间位阻和酯 基共同作用阻碍了亲核试剂攻击 $2 \mathrm{H}$-苯并吡喃. 并且当 $2 \mathrm{H}$-苯并吡喃芳环上的取代基供电子能力降低时(如引 入硝基), 其产物的产率也相应降低, 甚至无法发生. 作 者基于之前的工作基础提出了一种可能的反应机理: $2 \mathrm{H}$-苯并吡喃 52 的羟基被 $\mathrm{AlCl}_{3}$ 激活形成中间体 $\mathbf{5 5}$, 随 后消去 $\mathrm{AlCl}_{2} \mathrm{O}^{-}$产生碳正离子中间体 56, 受到烯基硅醚 的亲核进攻得到产物 4-取代-2-三氟甲基-3-乙氧甲酰基$4 H$-苯并吡喃 54. 尽管由于电子离域 2-位也是亲电位点, 但由三氟甲基的位阻导致烯醇硅醚进攻该位点的几率 大大降低.

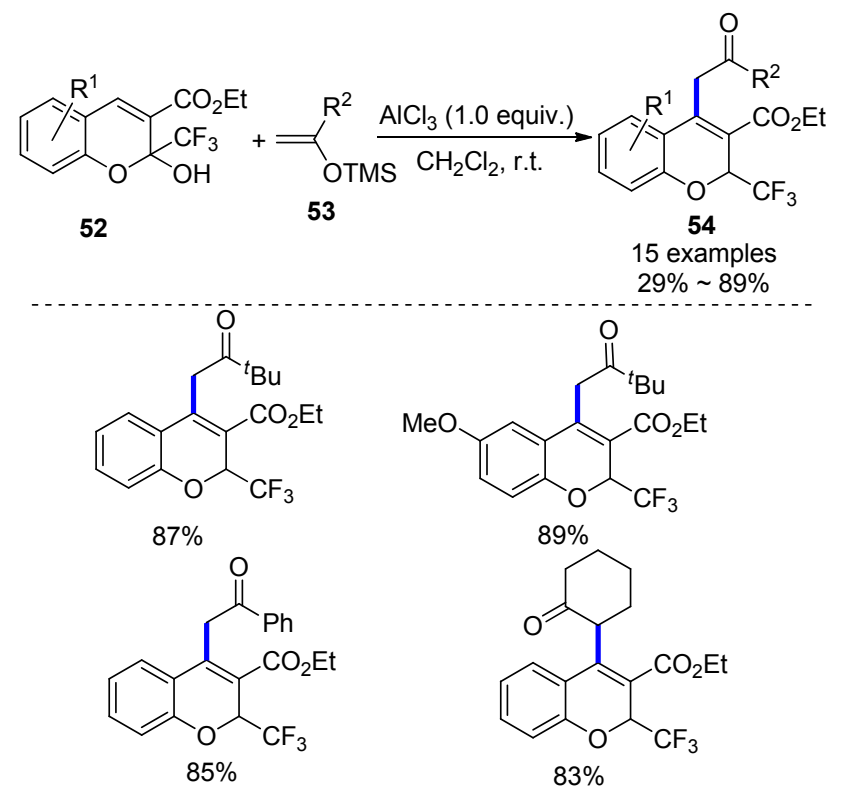

Mechanism

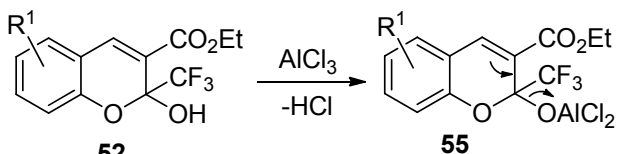

52

55

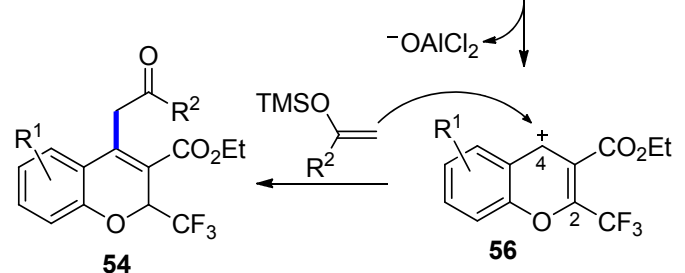

图式 $12 \mathrm{AlCl}_{3}$ 促进的 4-取代-2-三氟甲基-3-乙氧甲酰基-4H苯并吡喃的合成

Scheme 12 Synthesis of 4-functionalized-2-trifluoromethyl-3ethoxycarbonyl- $4 \mathrm{H}$-chromenes promoted by $\mathrm{AlCl}_{3}$

\section{$2.6 \mathrm{AlCl}_{3}$ 催化的跨环反应}

环丁烯胺具有高度的环张力, 与其他环系如环戊
酩，或者环己酮形成的并环结构在路易斯酸存在下可发 生环系的开环重构 ${ }^{[28]}$. 4,5-稠环丁烯酰胺在 $\mathrm{AlCl}_{3}$ 存在下 重排生成[2.2.1]-双环酮 58a. 4,6-稠环丁烯酰胺可以得到 [3.2.1]-双环酮 58b 和 58c (Scheme 13). 当氮上有一个长 链烯烃时，没有产生任何预期的桥环酮，而是生成了复 杂的氮杂并环酮 59. 通过使用密度泛函理论(DFT)计算 得出了 $\mathrm{AlCl}_{3}$ 促进的环系开环重排机理: 首先, 稠环丁 烯酰胺与 $\mathrm{AlCl}_{3}$ 的结合中间体 60 经过 $4 \pi$ 电环化开环得 到配位的环庚二烯酮 61, 进一步通过类 Nazarov 环化得 到中间体 62, 中间体 62 经过 1,2-烷基转移并最终离去 $\mathrm{AlCl}_{3}$ 得到[2.2.1]-双环酮 $\mathbf{5 8}$.

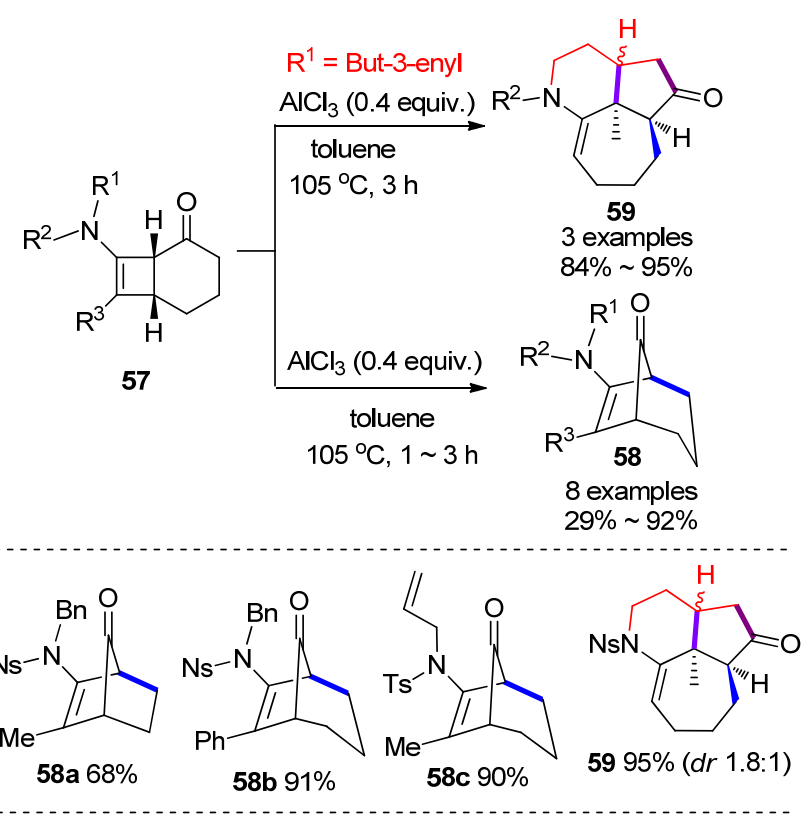

Mechanism

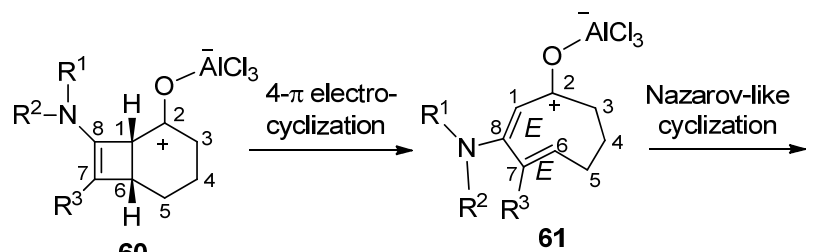

60
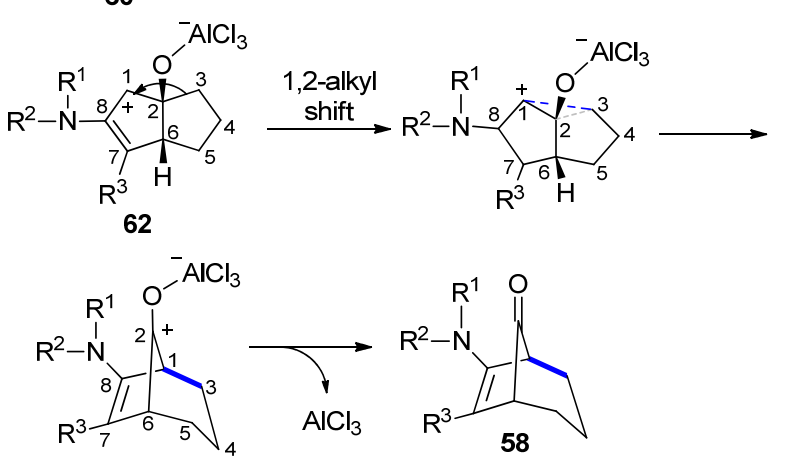

图式 $13 \mathrm{AlCl}_{3}$ 催化的 4,5-稠环丁烯酰胺的重排反应 Scheme $13 \mathrm{AlCl}_{3}$-catalyzed rearrangements of 4,5-fused cyclobutenamides 
2019 年, 宋西西课题组 ${ }^{[29]}$ 在前人工作的基础上, 在 温和的反应件下, 以 $\mathrm{AlCl}_{3}$ 促进螺环丙基巴比妥酸通过 Cloke-Wilson 重排反应生成各种具有潜在药用价值的二 氢呋喃 $[2,3-d]$ 嘧啶 64, 收率最高可达 98\% (Scheme 14). 由于巴比妥酸环上有两个路易斯酸的有效羰基结合位 点, 所以最初使用了 2 equiv. 的 $\mathrm{AlCl}_{3}$. 在扩展底物普适 性时发现, 苯环邻位的强吸电子取代基(如 $\mathrm{NO}_{2}$ 和 $\mathrm{CO}_{2} \mathrm{R}$ 等)对二氢呋喃 $[2,3-d]$ 嘧啶合成至关重要. 并由此提出 了反应机理: $\mathrm{AlCl}_{3}$ 促进环丙烷开环形成碳正离子中间 体 65, 碳正离子中间体 65 可被苯环上的邻位取代的硝 基或酯基等强吸电子基稳定和限制，从而有效保持环丙 烷中的反式构型, 最后碳正离子中间体 65 通过环化得 到二氢呋喃[2,3- $d$ 嘧啶衍生物 64 .
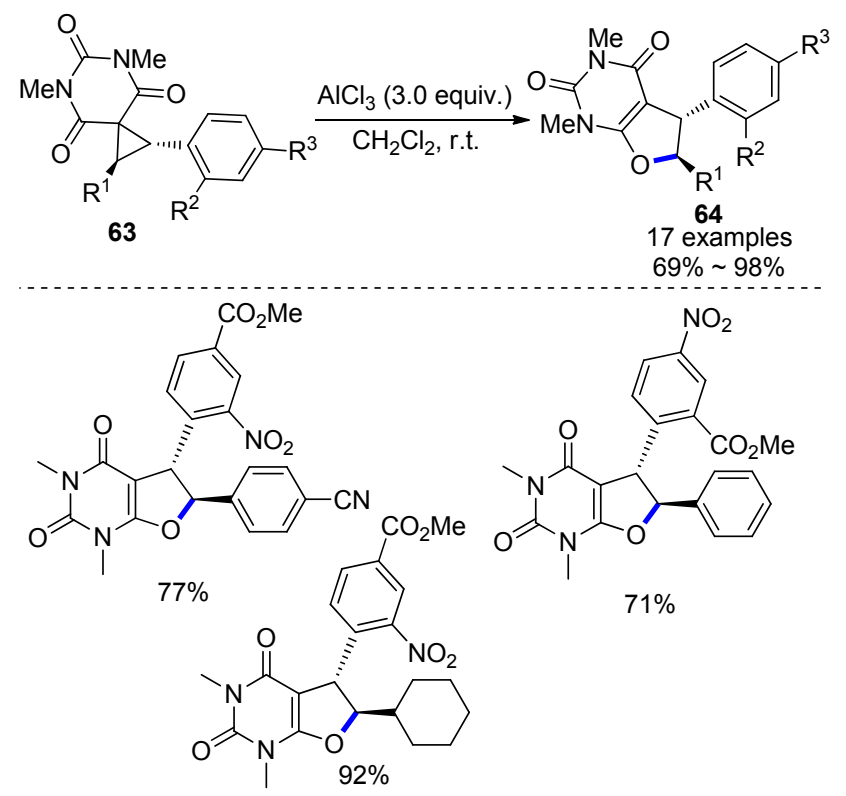

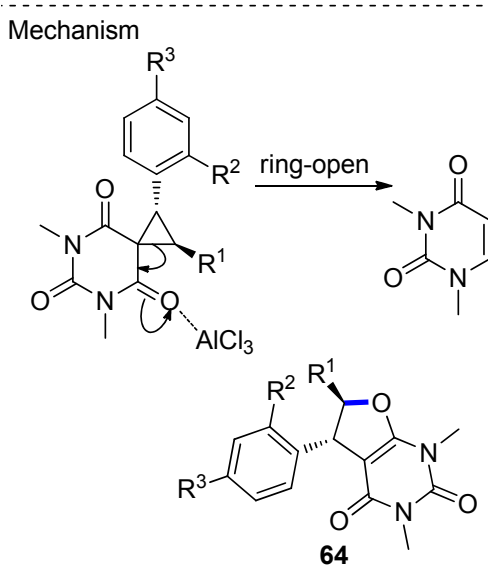

图式 $14 \mathrm{AlCl}_{3}$ 促进的二氢呋喃[2,3- $d$ 嘧啶的合成 Scheme 14 Synthesis of dihydrofuro[2,3- $d]$ pyrimidines promoted by $\mathrm{AlCl}_{3}$

2019 年, 郭春课题组 ${ }^{[30]}$ 报道了一种由 $\mathrm{AlCl}_{3}$ 促进环 丙烷衍生物开环合成取代苯并七元杂环衍生物的方法
(Scheme 15), 产物为酮式和烯醇式的混合物. 该方法具 有原子经济性高、底物范围宽、反应条件温和等特点，并 且克级反应收率依然不会降低. 选取得到的几种代表性 苯并 $[b]$-氧杂草酮对 5 种不同白念珠菌临床分离株进行 体外实验，结果表明该类结构具有选择性的抗真菌活 性. 对于反应机理, 他们认为 $\mathrm{AlCl}_{3}$ 与环丙烷衍生物的 羰基络合生成中间体 69, 并进一步引发环丙烷的开环 和环化, 形成中间体 70. 通过进一步的质子转移生成产 物, 它是烯醇式 67 和酮式 68 的混合物.

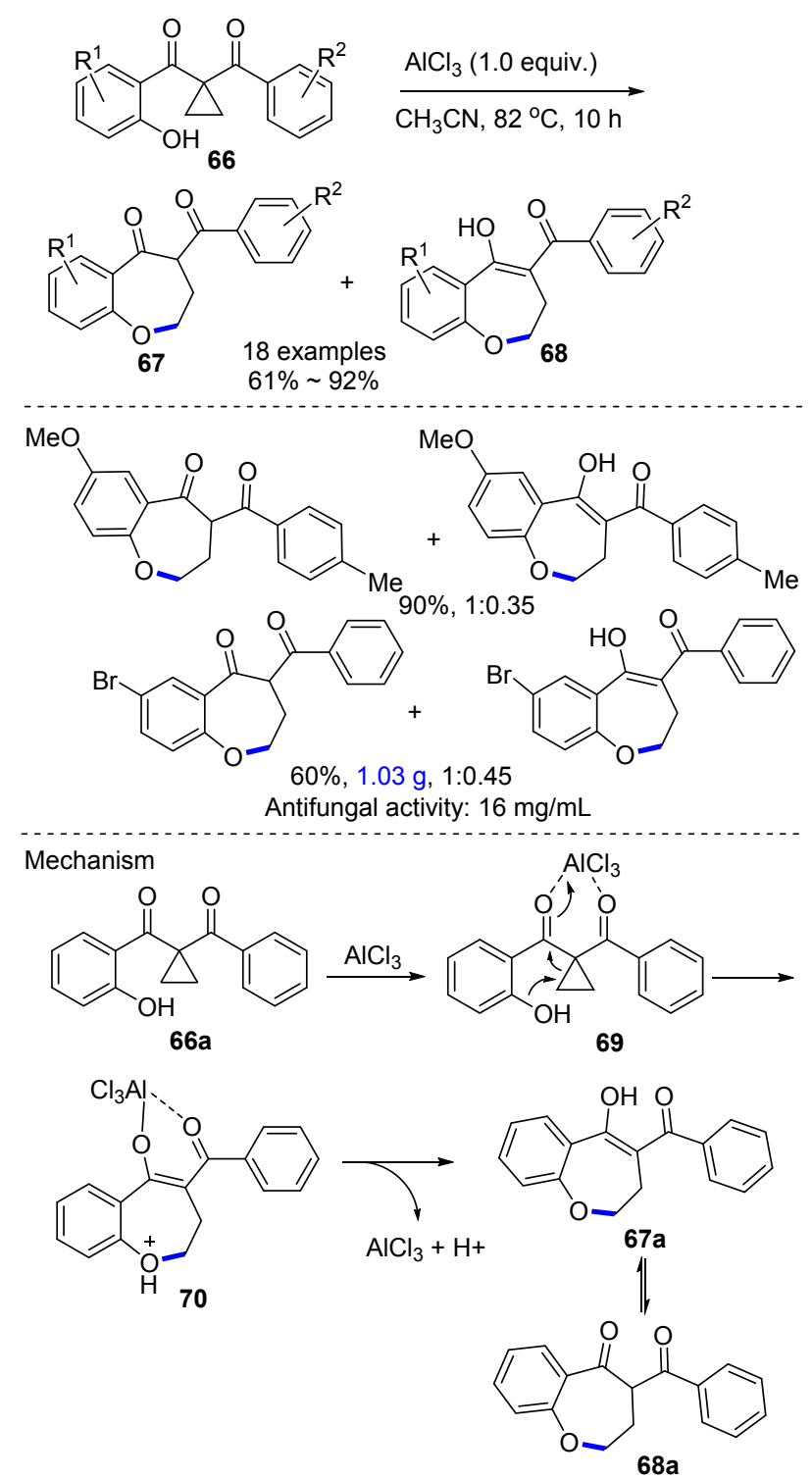

图式 $15 \mathrm{AlCl}_{3}$ 促进的 4-苯甲酰基-3,4-二氢苯并 $[b]$-氧杂草5(2H)-酮的合成

Scheme 15 Synthesis of 4-benzoyl-3,4-dihydrobenzo[b]-oxepin-5(2H)-one promoted by $\mathrm{AlCl}_{3}$

\section{$2.7 \mathrm{AlCl}_{3}$ 促进的偶联反应}

\subsubsection{C - $\mathrm{N}$ 偶联}

氮杂环卡宾 $(\mathrm{NHCs})$ 能够跟氧化亚氮 $\left(\mathrm{N}_{2} \mathrm{O}\right)$ 形成稳定 


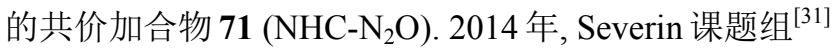
发展了一类在 $\mathrm{AlCl}_{3}$ 促进下, 使用氮杂环卡宾与 $\mathrm{N}_{2} \mathrm{O}$ 的 加合物 $\mathrm{NHC}-\mathrm{N}_{2} \mathrm{O}$ (71) 与芳烃通过 $\mathrm{C}-\mathrm{N}$ 偶联反应合成 多种偶氮咪唑类染料的方法(Scheme 16). 氮杂环卡宾 的氮原子上既可以是脂肪族也可以是芳香族的取代基, 此外未活化的氟苯、杂环甚至聚苯乙烯等聚合物均可与 71 偶联形成偶氮结构. 他们认为: $N H C-\mathrm{N}_{2} \mathrm{O}$ 的氧原子首 先与 $\mathrm{AlCl}_{3}$ 络合得到中间体 74, 随后 $\mathrm{AlCl}_{3}$ 从中间体 74 中夺走氧原子, 由此形成的高活性的重氮盐 75 与芳香 族化合物偶联得到偶氮咪唑类染料 73. 该方法证明了 $\mathrm{N}_{2} \mathrm{O}$ 可以间接作为有机合成中有效的 $\mathrm{N}_{2}$ 供体.

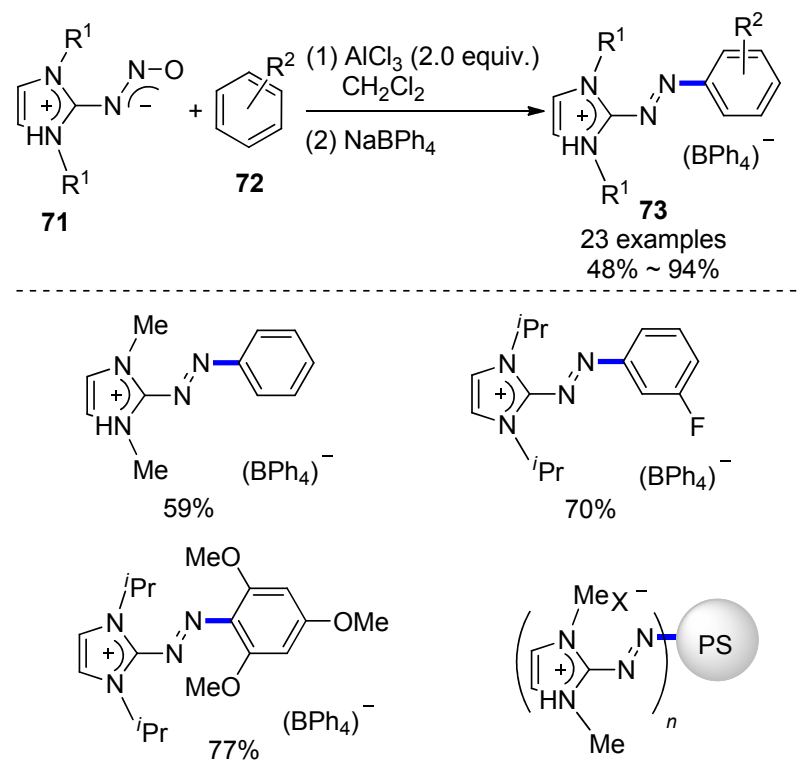

\section{Mechanism}

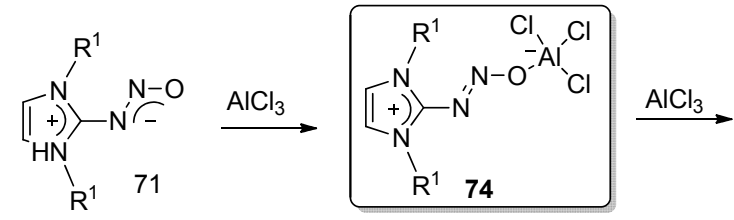<smiles></smiles>

图式 $16 \mathrm{AlCl}_{3}$ 促进的偶氮咪唑染料的合成

Scheme 16 Synthesis of azoimidazolium dyes promoted by $\mathrm{AlCl}_{3}$

\subsubsection{C-C 偶联}

同年, 黄志真课题组 ${ }^{[32]}$ 在 $\mathrm{AlCl}_{3}$ 催化下, 研究了 9着基呫吨 76 与酮或醛的偶联反应(Scheme 17). 反应条 件温和, 底物普适性良好, 各类脂肪族及芳香族酮及醛 均可达到中等及优良收率, 并且苯环上含富电子基团的 芳基甲基酮的产率比含缺电子基团的芳基甲基酮的产
率高. 进一步研究时发现，9-羟基噻吨也可以完成这种 转化. 并提出了用三氯化铝同时活化 9-羟基呫吨和酮或 醛的机理: $\mathrm{AlCl}_{3}$ 通过与 9-差基呫吨中的羟基氧原子配位 活化碳氧键，由此得到的中间体 80 中的碳氧键的断裂 形成碳正离子 $\mathbf{8 1}$, 在 $\mathrm{AlCl}_{3}$ 催化下醛或酮生成的烯醇 79 容易进攻碳正离子，得到的偶联产物 82 最后失水得到 所需产物并再生 $\mathrm{AlCl}_{3}$.
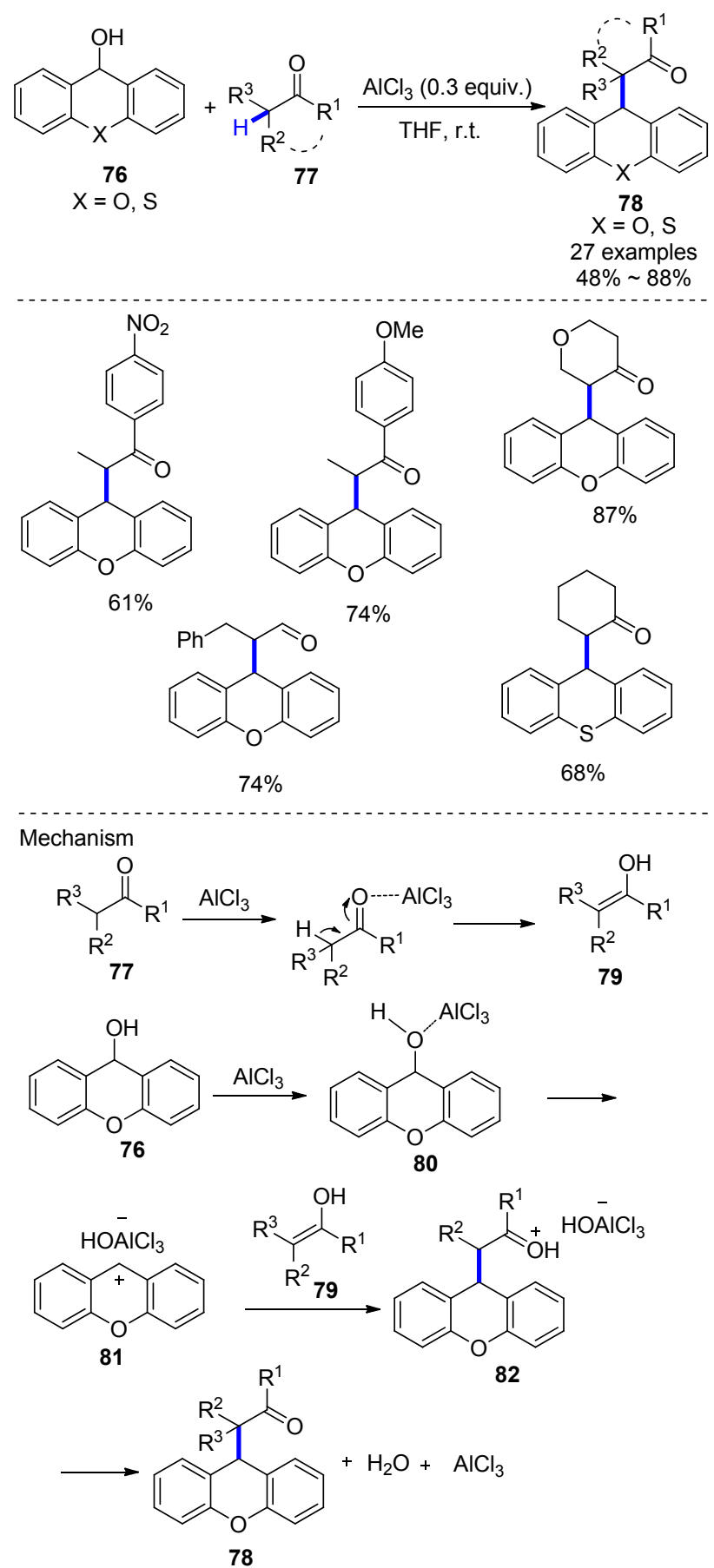

图式 $17 \mathrm{AlCl}_{3}$ 催化的 9-羟基呫吨与酮的偶联反应

Scheme $17 \mathrm{AlCl}_{3}$-catalyzed coupling reaction of $9 \mathrm{H}$-xanthen9-ols with ketones 


\section{$2.8 \mathrm{AlCl}_{3}$ 催化的分子间环加成反应}

Diels-Alder 反应是一类具有重要合成价值的有机 反应，其基本反应过程是是双烯体和亲双烯体通过 $[4+$ 2]环加成形成环已烯骨架. Diels-Alder 反应的立体选择 性通常仅限于内环加成产物选择性, 而外环加成产物选 择性较差. 目前在立体和对映选择性合成领域已经有了 一些进展，可通过改变反应催化剂或高取代的前体来控 制 Diels-Alder 反应内/外环加成产物比例. Loh 及 Fernández 课题组 ${ }^{[33]}$ 分别采用实验和理论计算的方法, 研究了 1,3-二烯与 $\alpha, \beta$-烯醛的 Diels-Alder 反应中, 路易 斯酸催化剂的种类和结构对内外环加成选择性的影响 (Scheme 18). 结果表明体积较小的 $\mathrm{AlCl}_{3}$ 在催化 1,3-二 烯与 $\alpha, \beta$-烯酫的 Diels-Alder 反应时, 主要生成 endo 环化 产物; 而使用体积较大的路易斯酸 $\mathrm{B}\left(\mathrm{C}_{6} \mathrm{~F}_{5}\right)_{3}$, 则主要得 到 exo 环合的骨架结构.

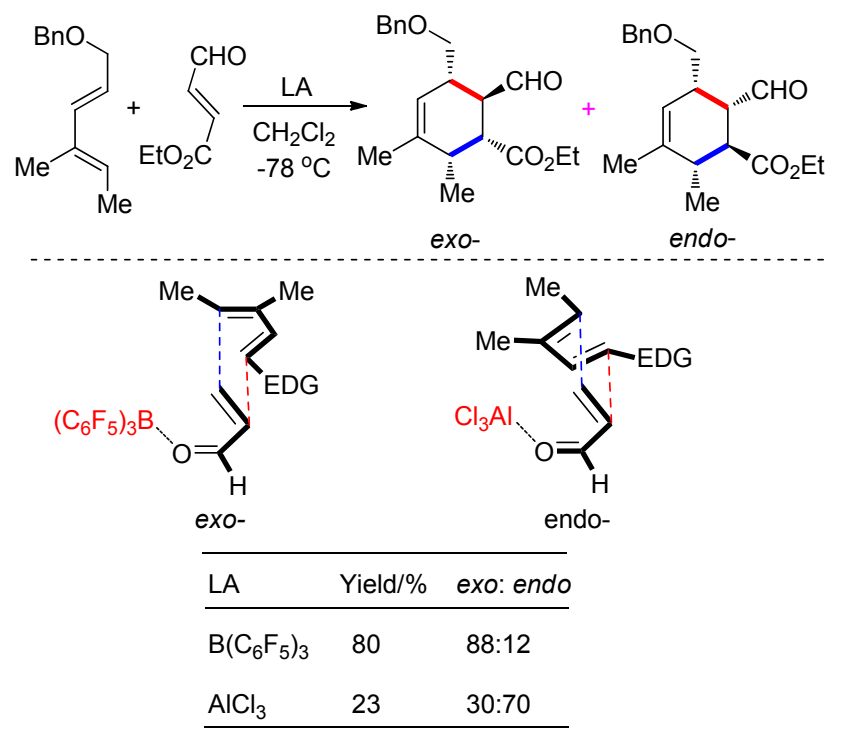

图式 18 路易斯酸催化 Diels-Alder 反应的内/外环加成选择性 Scheme 18 endo/exo cycloaddition selectivity of Lewis acid-catalyzed Diels-Alder reactions

近年来一些研究表明氧杂六元环也可以通过 Diels-Alder 环加成构建 ${ }^{[34]} .2017$ 年, 鲍红丽课题组 ${ }^{[35]}$ 对 $\mathrm{AlCl}_{3}$ 催化的 Oxa-Diels-Alder 反应进行了详细的研究 (Scheme 19). Diels-Alder 反应主要是由二烯的最高己占 分子轨道(HOMO)和亲二烯体(酫)的最低空分子轨道 (LUMO)之间的相互作用而发生：一方面未活化醛的 $\pi_{\mathrm{c}}=\mathrm{o}$ 的 LUMO 轨道比正常的亲二烯体能级高; 另一方 面, 与富含电子的二烯烃相比, 简单二烯烃的 HOMO 能 级较低. 由于能隙差较大, 两者的 Diels-Alder 环化过程 更具挑战性. 通过催化量的 $\mathrm{AlCl}_{3}$ 对醛的活化作用, 可 显著降低醛的 LUMO 能级, 使得该环加成反应在 $80{ }^{\circ} \mathrm{C}$ 条件下即可发生得到二氢吡喃衍生物.
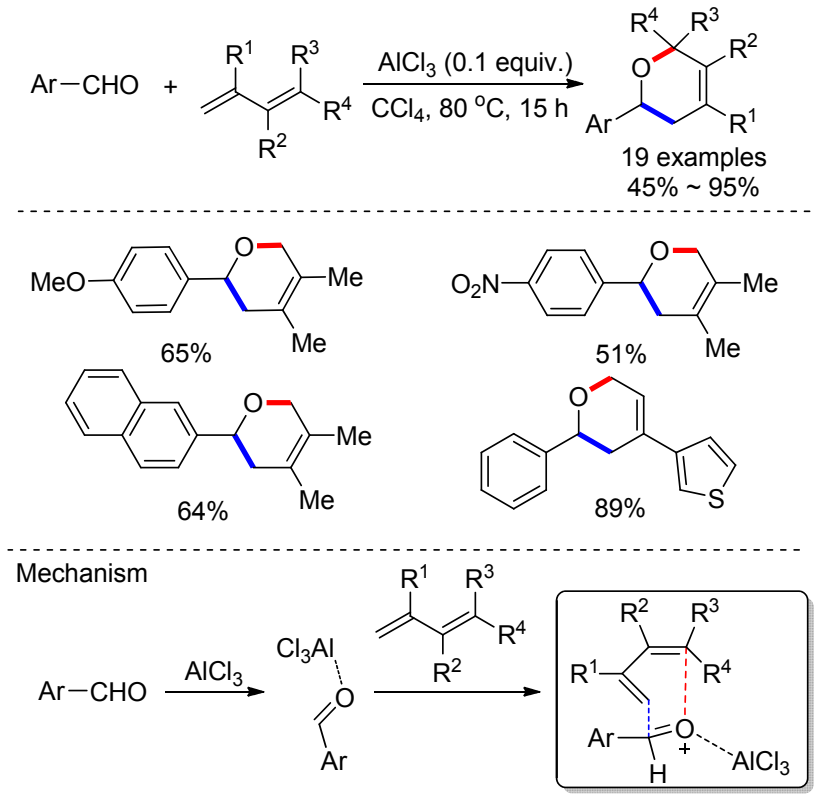

图式 $19 \mathrm{AlCl}_{3}$ 催化的二氢吡喃的合成

Scheme $19 \mathrm{AlCl}_{3}$-catalyzed synthesis of dihydropyrans

含有吸电子基团的环丙烷骨架由于环张力的原因, 在三氯化铝作用下极易发生开环反应，可利用环丙烷与 醛酮的 $[3+2]$ 环加成反应，合成多种杂环骨架. 2,3-二取 代环丙烷-1,1-二酯由于其环上所带的活性基团更多, 因 此更能增加产物结构的多样性与复杂性, 为构建结构复 杂的四氢呋喃环提供便捷的渠道. 根据这一性质，杨高 升课题组研究了在 $\mathrm{AlCl}_{3}$ 催化下, 多种 2,3-二取代环丙 烷-1,1-二甲酸酯与醛或酮通过 $[3+2]$ 环加成合成 2,3,3,4,5-五取代四氢呋喃和(螺)四氢呋喃衍生物的反应 (Scheme 20). 可以通过不同电子性质的醛与反式-2,3-二 取代的环丙烷-1,1-二甲酸二甲酯反应获得顺式一五取代 四氢呋喃或反式一五取代四氢呋喃 $\mathbf{8 4 a}^{[36]}$. 当使用顺式2,3-二取代-1,1-二甲酸二甲酯进行该反应时，可以生成 单一的非对映异构体五取代四氢呋喃衍生物 $\mathbf{8 4} \mathbf{b}^{[37]}$. 将 反应扩展到环状/无环脂肪族酮时, 可以顺利得到多取 代的反式-(螺)四氢呋喃衍生物 $\mathbf{8 5}^{[38]}$. 基于以上工作, 通过胡椒醛和荺芦醛得到的五取代四氢呋喃 $84 \mathrm{c}$ 可以进 一步合成呋喃木脂素天然产物 $( \pm)$-urinaligran 以及 (土)-virgatusin 的异构体 $(\mathbf{8 6})^{[39]}$.

除了醛酮类，在 $\mathrm{AlCl}_{3}$ 存在下，环丙烷二酯也可与 含有硫羰基的结构发生环加成反应. 2017 年 Werz 课题 组 ${ }^{[00}$ 报道了在温和的条件下 $\mathrm{AlCl}_{3}$ 催化 1,1-环丙烷二甲 酸二甲酯与硫酮的 $[3+2]$ 环加成反应得到多取代四氢噻 吩 89 (Scheme 21). 各种取代的 1,1-环丙烷二甲酸二甲 酯与硫酮均可完成这种转化, 收率最高可达 $99 \%$. 在类 似的条件下，硒酮也可以成功地转化为多取代四氢硒吩 衍生物. 值得一提的是, 如果将硫羰基与环丙烷结构连 


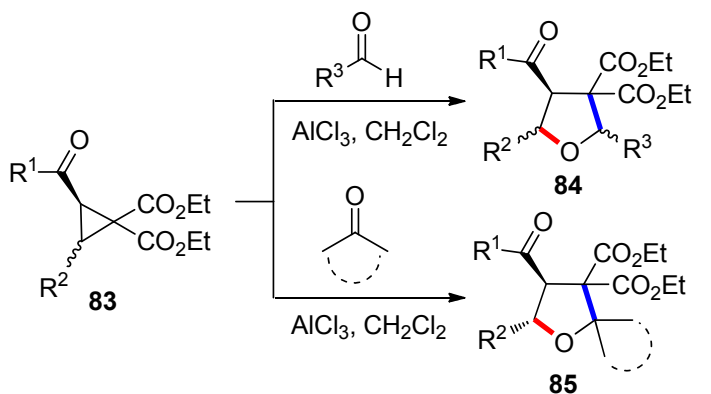

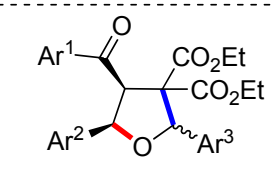

$84 a$

23 examples $19 \% \sim 90 \%$<smiles>[R]Oc1ccc([C@@H]2O[C@H](c3ccc4c(c3)OCO4)[C@H](C(=O)N3CCOC3=O)C2(C)C(=O)OCC)cc1O[R]</smiles>

2 examples $91 \% \sim 92 \%$

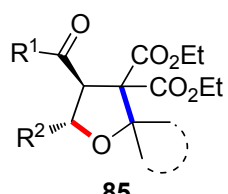

23 examples $54 \% \sim 96 \%$

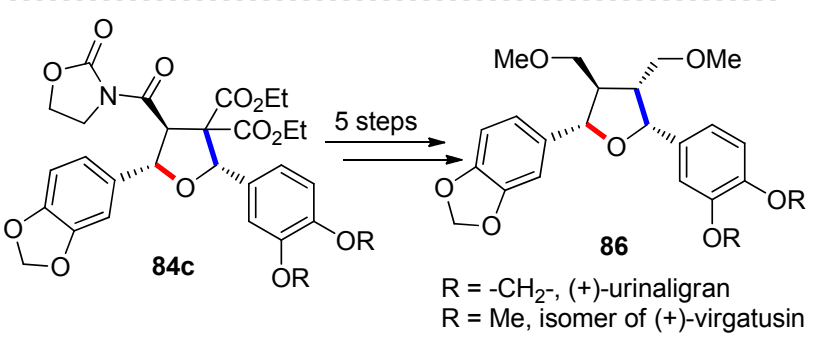

$\mathrm{R}=\mathrm{Me}$, isomer of $(+)$-virgatusin

图式 $20 \mathrm{AlCl}_{3}$ 催化的 2,3-二取代环丙烷-1,1-二甲酯的环加成 反应

Scheme $20 \quad \mathrm{AlCl}_{3}$-catalyzed cycloaddition reaction of 2,3disubstituted cyclopropane1,1-dicarboxylates

接在同一个分子内, 还可以通过该方法构建硫桥 [n.2.1] 双环体系 91. 作者推测这些转化主要是由于 $\mathrm{AlCl}_{3}$ 与酯 基的络合作用促进了环丙烷骨架的开环，完成了上述的 环加成反应.

\section{$2.9 \mathrm{AlCl}_{3}$ 促进的氰基化反应}

2016 年, 康彦彪课题组 ${ }^{[4]}$ 报道 $\mathrm{AlCl}_{3}$ 促进 $\mathrm{C}\left(\mathrm{sp}^{3}\right)$ $\mathrm{C}\left(\mathrm{sp}^{2}\right)$ 键断裂脱酰基, 实现酮和醛的氧化胺化得到脂肪 族与芳香族氰衍生物 93 的反应(Scheme 22). 该反应以 廉价易得的 $\mathrm{NaNO}_{2}$ 为氧化剂和氮源, 避免了剧毒氰化 物, 并且反应条件温和, 顺利得到含芳基、杂芳基、烷 基和烯基的腈. 通过动力学同位素效应和控制实验, 他 们认为反应在 $\mathrm{AlCl}_{3}$ 存在下, 醛或酮与亚硝基反应得到 中间体 94, 并迅速异构化为中间体 95, 通过三氯化铝与 氧的配位活化分子使 $\mathrm{C}-\mathrm{C}$ 键断裂得到氰衍生物 93 .
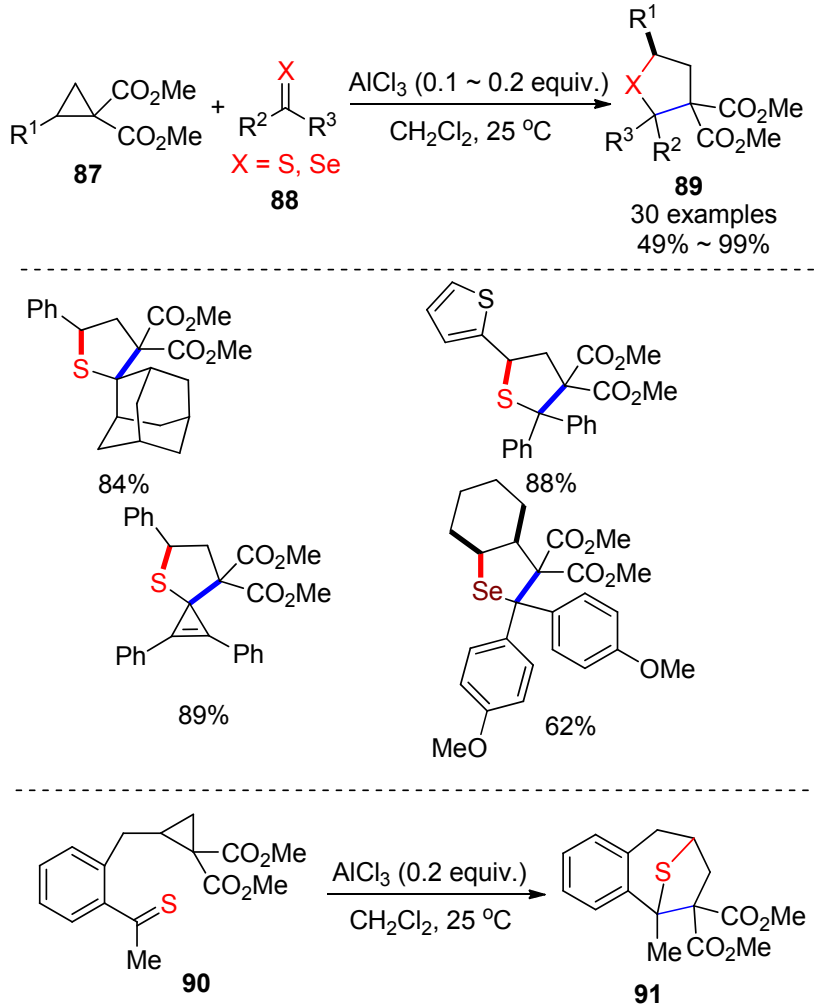

图式 $21 \mathrm{AlCl}_{3}$ 催化的四氢噻吩的合成

Scheme $21 \mathrm{AlCl}_{3}$-catalyzed synthesis of tetrahydrothiophenes

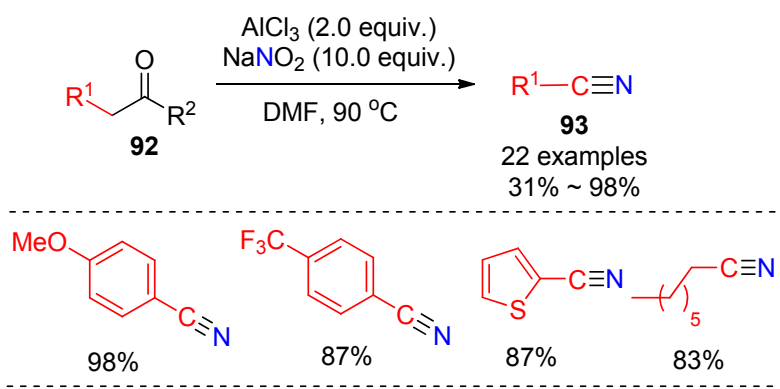

Mechanism
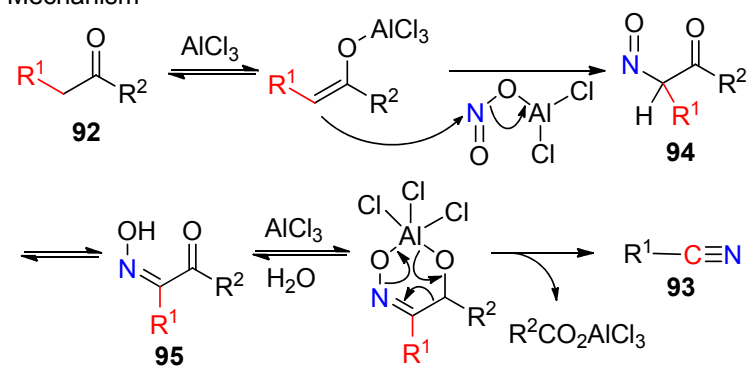

图式 $22 \mathrm{AlCl}_{3}$ 促进的氰类衍生物的合成

Scheme 22 Synthesis of nitriles promoted by $\mathrm{AlCl}_{3}$

\section{$2.10 \mathrm{AlCl}_{3}$ 促进的串联反应}

含氟基团可以极大地影响药物分子的物理、化学和 生物特性从而增强药物代谢稳定性和选择性, 在现代生 物有机化学中受到越来越多的关注. 利用廉价易得的三 氟乙酸及其钠盐与酸酐作为三氟甲基来源进行三氟甲 
基化，是合成三氟甲基化合物的一种有效的方法. 2018 年, 翁志强课题组 ${ }^{[42]}$ 报道了吡咯烷酮与三氟乙酸酐之 间由 $\mathrm{AlCl}_{3}$ 促进的串联反应. 通过三氯化铝辅助下的三 氟乙酰化、亲核氯化及消去等过程, 得到了结构多样的 1-氯-2,2,2-三氟乙基取代吡咯烷酮 98 (Scheme 23). 并完 成了产物的克级制备. 对于反应机理, 作者认为 $\mathrm{AlCl}_{3}$ 促进了三氟乙酰基正离子 100 产生以及 2-吡咯烷酮的烯 醇式中间体 99 的酰基化, 得到的中间体 101 经过去质子 得到了三氟乙酰基 2-吡咯烷酮衍生物 102. 随后, $\mathrm{AlCl}_{3}$ 通过活化羰基促进了氯化反应的进行, 最后通过消去 $\mathrm{AlCl}_{2} \mathrm{OH}$ 得到 1-氯-2,2,2-三氟乙基取代吡咯烷酮 98.

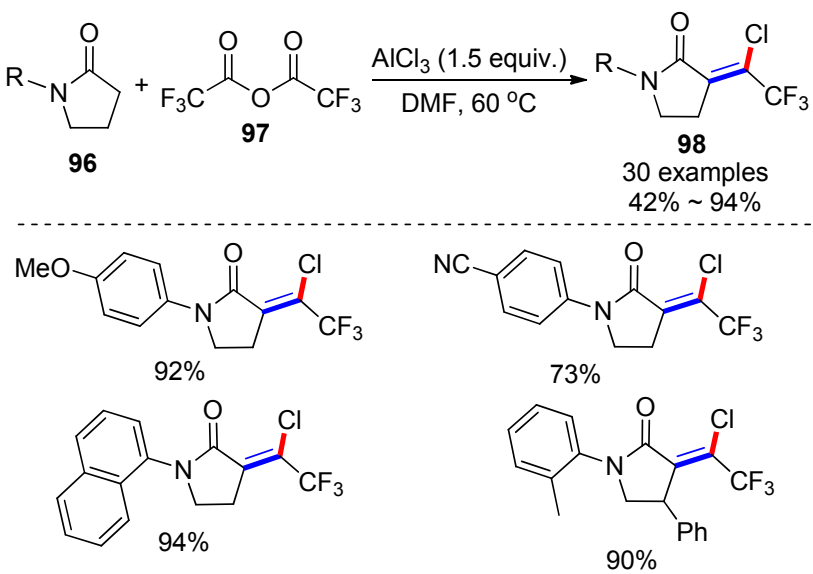

$$
\text { Mechanism }
$$<smiles>[R]N1C[C@H](CC)CC1=O</smiles>

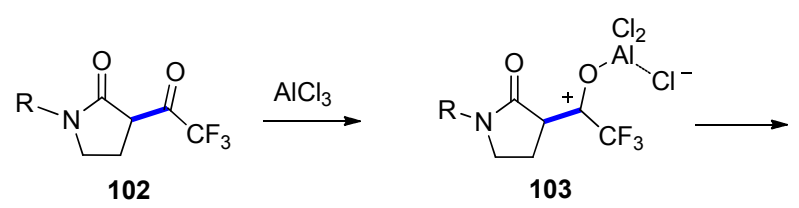<smiles>[R]N1CCC(=C(Cl)C(F)(F)F)C1=O</smiles>

图式 $23 \mathrm{AlCl}_{3}$ 促进的 1-氯-2,2,2-三氟乙基取代吡咯烷酮的合 成

Scheme 23 Synthesis of 1-chloro-2,2,2-trifluoroethylidenesubstituted pyrrolidones promoted by $\mathrm{AlCl}_{3}$

\section{$2.11 \mathrm{AlCl}_{3}$ 催化的多组分反应}

多组分反应可以实现快速大量地合成许多结构复 杂多样的化合物并建立相应的化合物库, 因此, 多组分 反应越来越成为合成化学的重要工具而受到化学合成
界的广泛关注和重视. Passerini 反应主要通过醛、异腈 和羧酸或者醇合成 $\alpha$-酰氧基酰胺或者 $\alpha$-烷氧基酰胺 ${ }^{[43]}$. 2015 年, 汪君课题组 ${ }^{[44]}$ 报道了 $\mathrm{AlCl}_{3}$ 催化异氧、肉桂醛 和醇生成 $\alpha$-烷氧基- $\beta, \gamma$-烯酰胺衍生物 108 的 $O$-烷基化的 Passerini 反应(Scheme 24). 值得一提的是, 该反应中醇 既是反应底物又是反应溶剂. 各类醇类均可提供相应的 功能性 $\alpha$-烷氧基- $\beta, \gamma$-烯酰胺衍生物. 在底物普适研究时 发现，肉桂醛衍生物芳环上取代基的电子性质对产率有 较大影响：供电子基团较吸电子基团产率更高. 在 $\mathrm{AlCl}_{3}$ 催化下，肉桂醛与醇反应生成羰基化合物 109, 并 失去一个水分子. 随后，异氭进攻羰基化合物 109 的羰 基碳生成中间体 110. 最后，由中间体 110 水解生成的 111 容易异构化生成 $\alpha$-烷氧基- $\beta, \gamma$-烯酰胺 108a.

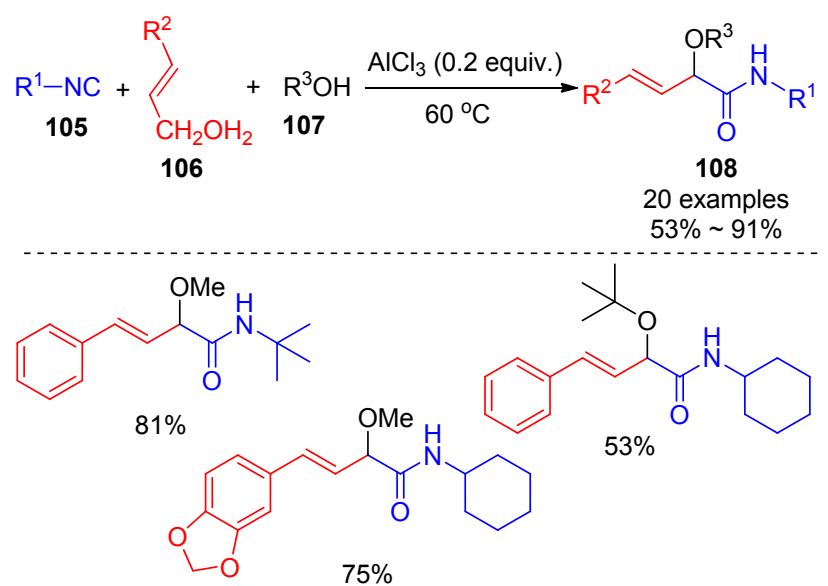<smiles>CO[C@H](C#[N+]Cl)C(=O)NC1CCCCC1C=Cc1ccccc1</smiles>

图式 $24 \mathrm{AlCl}_{3}$ 催化的 $\alpha$-烷氧基- $\beta, \gamma$-烯酰胺的合成 Scheme $24 \mathrm{AlCl}_{3}$-catalyzed synthesis of $\alpha$-alkoxy- $\beta, \gamma$-enamides

4-芳基- $N H$-1,2,3-三唑通常使用硝基烯烃与 $\mathrm{NaN}_{3}$ 缩 合得到. 然而, 硝基烯烃的不易获得性一直限制着三唑 结构的合成. 2016 年, 陈云峰课题组 ${ }^{[45]}$ 报道了一种由 $\mathrm{AlCl}_{3}$ 催化的芳香醛、硝基烷烃和 $\mathrm{NaN}_{3}$ 三组分缩合反应 得到 4-芳基- $N H$-1,2,3-三唑的方法, 并表现出对多种官 能团的优良耐受性(Scheme 25). 与前人的工作相比，该 
方法除了反应原料容易获得外，还避免了硝基烯烃中间 体的制备与分离，从而提高了反应收率与普适性. 控制 实验研究表明, $\mathrm{AlCl}_{3}$ 通过激活硝基与醛形成硝基烯烃中 间体，进一步活化硝基与叠氮化钠环化形成三唑结构.

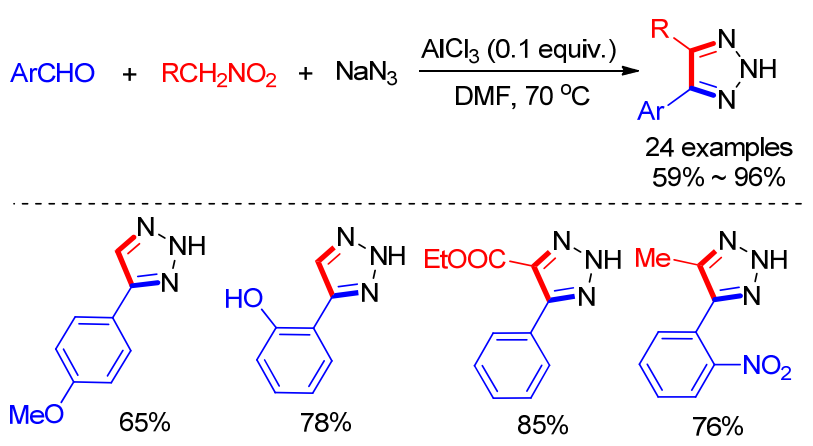

图式 $25 \mathrm{AlCl}_{3}$ 催化的 4-芳基- $N H$-1,2,3-三唑的合成

Scheme $25 \mathrm{AlCl}_{3}$-catalyzed synthesis of 4-aryl- $\mathrm{NH}-1,2,3-$ triazoles

\section{$2.12 \mathrm{AlCl}_{3}$ 促进的聚合反应}

除了能活化羰基氧以外, 醚类的氧原子也可被三氯 化铝活化. 2012 年, Faust 课题组 ${ }^{[46]}$ 报道了 $\mathrm{H}_{2} \mathrm{O} / \mathrm{AlCl}_{3}$ • $\mathrm{R}_{2} \mathrm{O}$ 共引发剂体系引发异丁烯(IB)的聚合反应, 可高选 择性地将其转化为含有 $e x o$-端烯的聚异丁烯 114, 并证 实了使用异丙醚 $\left({ }^{i} \mathrm{Pr}_{2} \mathrm{O}\right)$ 时异丁烯的转化率最高 (Scheme 26). 当分别加入 $\mathrm{AlCl}_{3}$ 和二烷基醚时, 仅能得到三取代 烯基为主的常规聚异丁烯 115. 机理研究表明, 水与

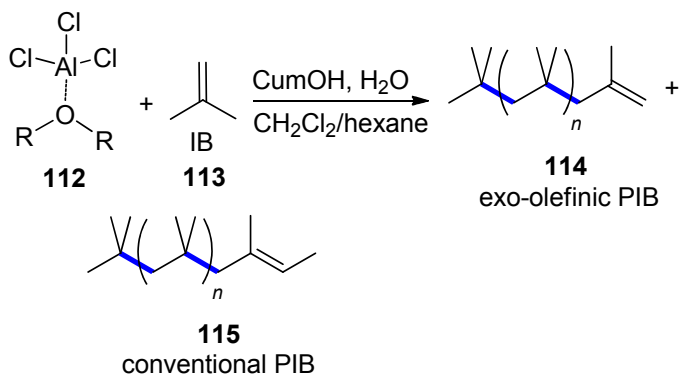

Mechanism

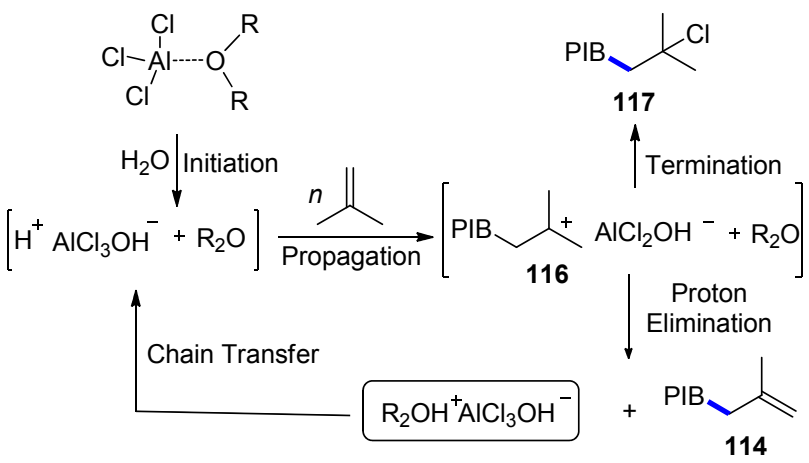

图式 $26 \mathrm{AlCl}_{3} \cdot \mathrm{R}_{2} \mathrm{O}$ 与水共引发的异丁烯聚合反应 Scheme 26 Polymerization of isobutylene initiated by $\mathrm{AlCl}_{3}$. $\mathrm{R}_{2} \mathrm{O}$ and $\mathrm{H}_{2} \mathrm{O}$
$\mathrm{AlCl}_{3} \cdot \mathrm{R}_{2} \mathrm{O}$ 络合物 112 反应生成 $\mathrm{H}^{+} \mathrm{AlCl}_{3} \mathrm{OH}^{-}$，同时释放 二烷基醚. $\mathrm{H}^{+} \mathrm{AlCl}_{3} \mathrm{OH}^{-}$引发聚合反应生成含有外烯烃 的聚异丁烯 114, 并再生 $\mathrm{H}^{+} \mathrm{AlCl}_{3} \mathrm{OH}^{-}$完成循环. 当中间 体 116 生成 $\mathrm{PIB}-\mathrm{Cl}$ (117)与 $\mathrm{AlCl}_{2} \mathrm{OH}$ 时, 由于 $\mathrm{AlCl}_{2} \mathrm{OH}$ 导致共引发剂的整体失活，从而使循环终止.

\section{$2.13 \mathrm{AlCl}_{3}$ 促进的其他反应类型}

2015 年, 毛金成课题组 ${ }^{[47]}$ 报道了一种以二叔丁基 过氧化物(DTBP)为氧化剂, $N, N$ 二 二甲基甲酰胺为底物, 以磺酰肼为硫源，通过 $\mathrm{AlCl}_{3}$ 促进体系合成 $S$-芳基硫代 氨基甲酸酯 120 的方法(Scheme 27). 提出了 $\mathrm{AlCl}_{3}$ 促进 磺酰肼脱氢脱氧的机理：首先，DTBP 在加热时产生叔 丁氧基自由基 121, 可吸收 $N, N$-二甲基甲酰胺的氢自由 基生成酰基自由基 122. 在 $\mathrm{AlCl}_{3}$ 的作用下，苯磺酰肼中 依次失去氢、氧原子以及 $\mathrm{N}_{2}$, 形成芳基二硫化物 123 . 酰

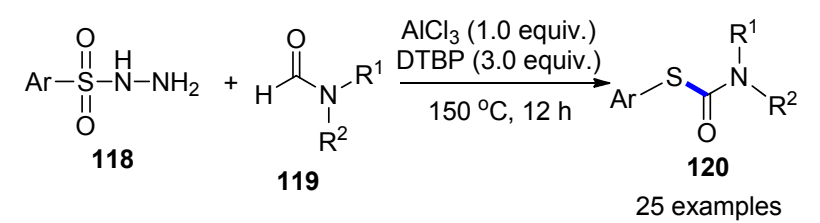
$35 \% \sim 66 \%$
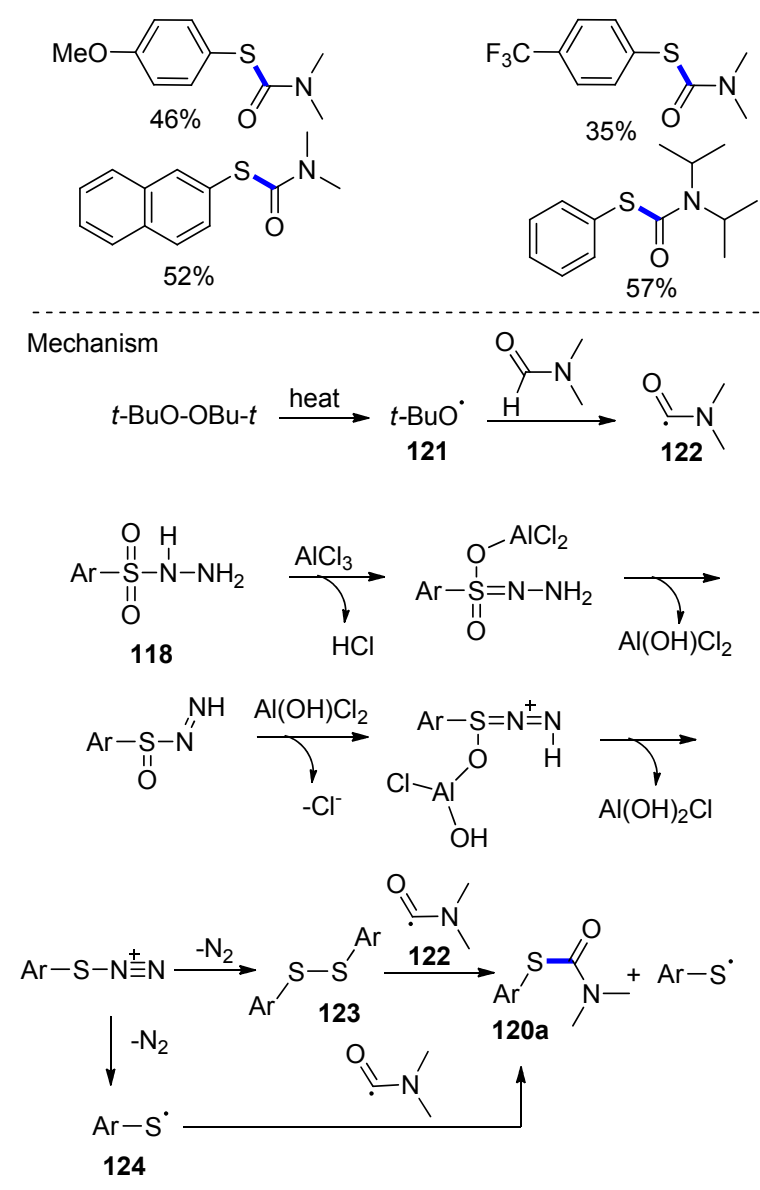

图式 $27 \mathrm{AlCl}_{3}$ 促进的 $S$-芳基硫代氨基甲酸酯的合成 Scheme $27 \quad \mathrm{AlCl}_{3}$-promoted synthesis of $S$-aryl thiocarbamates 
基自由基 122 与芳基二硫化物 123 或硫醚苯硫基自由基 124 发生反应，形成产物 $S$-芳基硫代氨基甲酸酯 $120 \mathrm{a}$ 并 产生另一个硫自由基 124, 继续进行下一步的反应.

\section{3 对氮的活化作用}

\section{$3.1 \mathrm{AlCl}_{3}$ 催化的加成反应}

2014 年, 徐凡课题组 ${ }^{[48]}$ 在他们研究靛红 3-位亲核 加成反应工作的基础上, 利用 $\mathrm{AlCl}_{3}$ 催化 2-甲基吡啶与

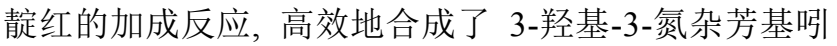
哚-2-酮 127 (Scheme 28). 同时他们对这种方法的高效 性和通用性做了相关研究, 发现无论靛红苯环上的取代 基是吸电子基团还是供电子基团, 反应都可以顺利地进 行. 为了深入地了解 $\mathrm{AlCl}_{3}$ 催化该反应的实质, 他们利 用原位核磁共振的方法对 $\mathrm{AlCl}_{3}$ 与 2-甲基吡啶相互作用 前后分子内特征质子的化学位移变化进行跟踪, 结果表 明 $\mathrm{AlCl}_{3}$ 与 2-甲基吡啶中的 $\mathrm{N}$ 原子发生了有效络合. 结 合该实验结果与相关文献, 他们认为 $\mathrm{AlCl}_{3}$ 与 2-甲基吡 啶中的氮配位生成活性中心 128 , 活化甲基 $\mathrm{C}-\mathrm{H}$ 键. $\mathrm{C}-\mathrm{H}$ 键断裂形成的中间体 129 的双键端基碳进攻靛红 的酮羰基, 得到的中间体 $\mathbf{1 3 0}$ 中的 $\mathrm{Al}-\mathrm{O}$ 键断裂得到产

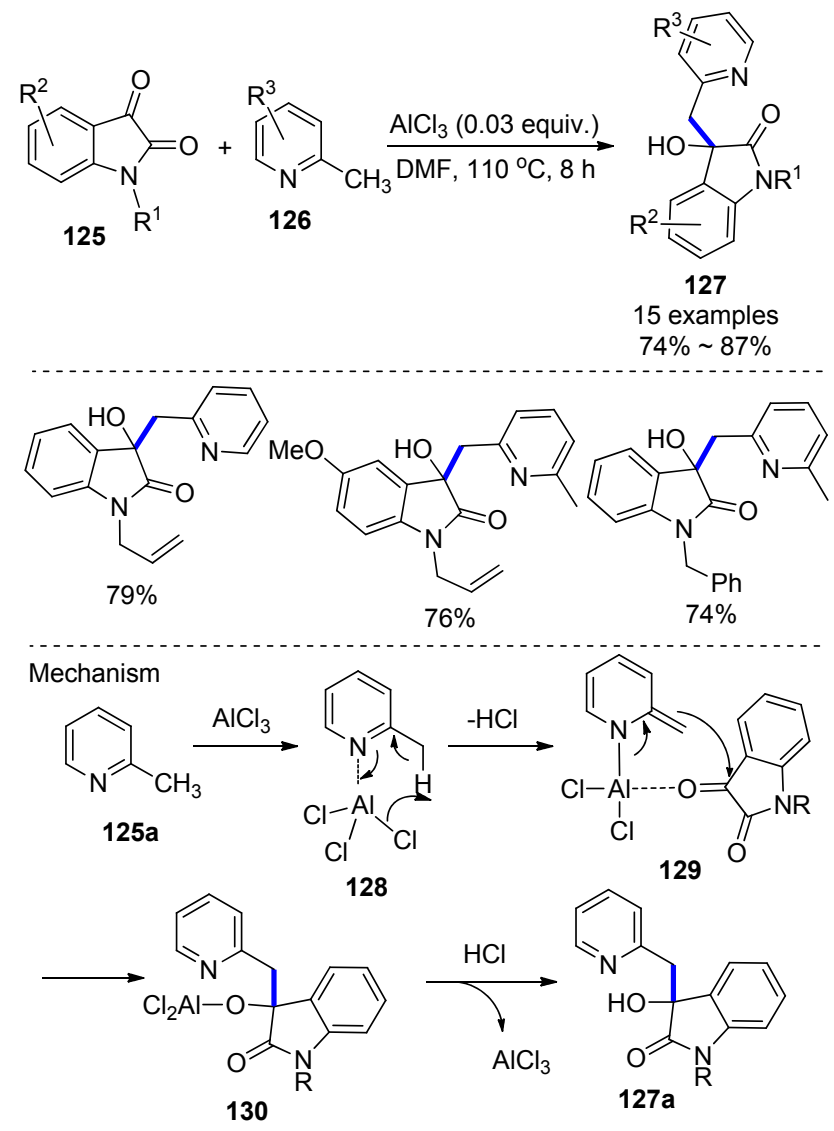

图式 $28 \mathrm{AlCl}_{3}$ 催化的 3-羟基-3-氮杂芳基吲哚-2-酮的合成

Scheme $28 \quad \mathrm{AlCl}_{3}$-catalyzed synthesis of 3-azaarene-substituted 3-hydroxy-2-oxindoles
物 3-羟基-3-氮杂芳基吲哚-2-酮 127a, 释放出的 $\mathrm{AlCl}_{3}$ 进入下一个催化循环. 值得一提的是, 活性中心 129 通 过与靛红羰基的配位还起到了活化了靛红羰基的作用.

\section{$3.2 \mathrm{AlCl}_{3}$ 催化的环化反应}

2016 年, 李月明课题组 ${ }^{[49]}$ 报道了一种 $\mathrm{AlCl}_{3}$ 催化的 $N$-烯丙基对甲苯磺酰胺通过氮杂 Prins 环化反应合成反 式-2-取代-4-卤代哌啶 133 的方法(Scheme 29). 他们发 现以 $\mathrm{AlCl}_{3}$ 为催化剂, 氯、溴、碘三甲基硅烷为卤化物 源, $N$-烯丙基对甲苯磺酰胺与醛类的氮杂 Prins 环化可以 很容易实现, 从而获得高收率和非对映选择性的反式卤 代哌啶. 然而使用三氟化嗍为氟源时, 由于氟离子的体 积很小，在氟化物攻击反应中间体的过程中，氟离子的 非对映选择性很差. 值得一提的是, 当使用丁烯-1-醇进 行 Prins 环化时, 得到了高非对映选择性和收率的顺式 4-卤代吡喃. 他们认为氮杂-Prins 环化的反式选择性可 能归因于 $\mathrm{Ts}$ 和 $\mathrm{R}$ 基团之间的空间排斥作用. 由于这种 排斥作用, $\mathrm{AlCl}_{3}$ 通过与氮配位并与醛反应得到中间体 134. 氮杂-Prins 环化通过六元环过渡态 135 进行，Ts 基 才在平伏位置, $\mathrm{R}$ 基团在轴向位置, 卤化物阴离子从平 伏方向进攻, 致使反式卤代哌啶 133a 为主要产物.

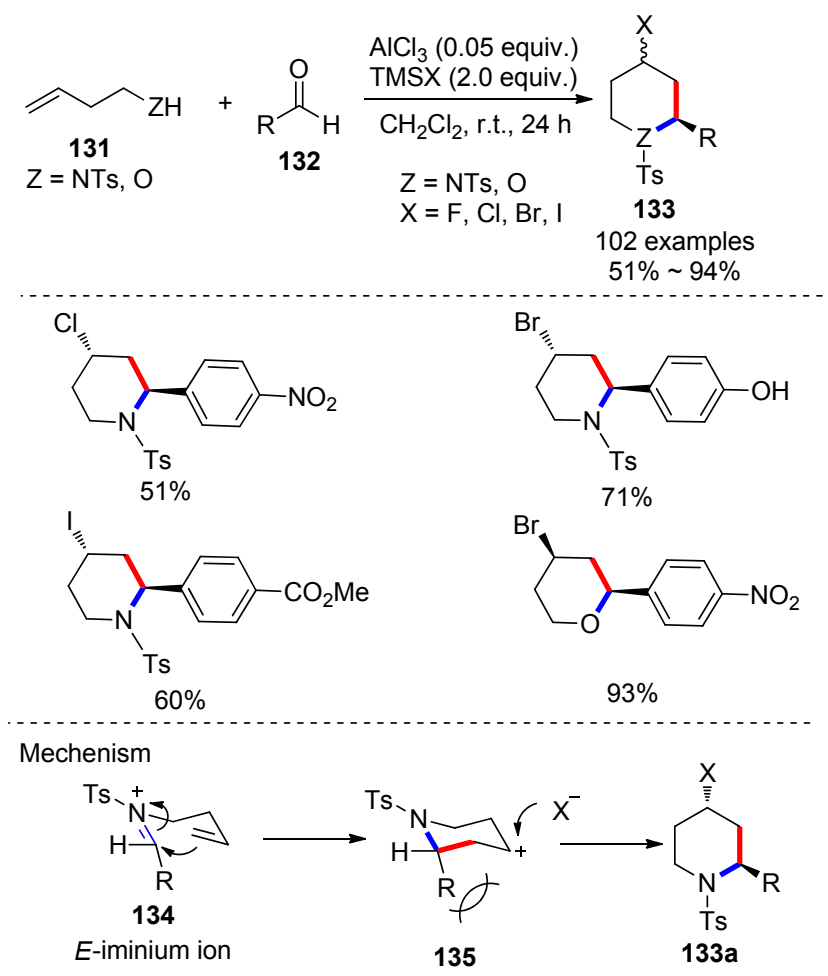

图式 $29 \mathrm{AlCl}_{3}$ 催化的反式-2-取代-4-卤代哌啶的合成 Scheme $29 \mathrm{AlCl}_{3}$-catalyzed synthesis of trans-2-substituted4-halopiperidines

\section{$3.3 \mathrm{AlCl}_{3}$ 促进的(杂)芳基化反应}

2012 年, $\mathrm{Pal}$ 课题组 ${ }^{[50]}$ 报道了一种 $\mathrm{AlCl}_{3}$ 促进 2,3-二 氯代喹喔啉(杂)芳基化的反应(Scheme 30). 通过调控加 
入的芳基化试剂的种类及比例可以控制反应生成单(杂) 芳基喹喔啉 137、对称型和非对称型 2,3-二(杂)芳基喹喔 啉 138, 139. 值得注意的是, 这是首例使用 $\mathrm{AlCl}_{3}$ 催化实 现喹喔啉(杂)芳基化的方法, 并且由于(杂)芳基喹喔啉 上氯原子的存在, 还可以进行其它转化, 如 Sonogashira 偶联等. 通过对反应机理的研究, (杂)芳基化反应始于 $\mathrm{AlCl}_{3}$ 对 2,3-二氯喹喔啉的一个氮原子活化得到中间体 140, 然后芳烃或异芳烃对活化后的亚胺正离子亲核加 成得到中间体 141, 最后释放 $\mathrm{AlCl}_{3}$, 得到所需的产物 137. 同样, $\mathrm{AlCl}_{3}$ 与另一个氮原子的配位促进了 2,3-二 (杂)芳基喹喔啉 138,139 的形成.
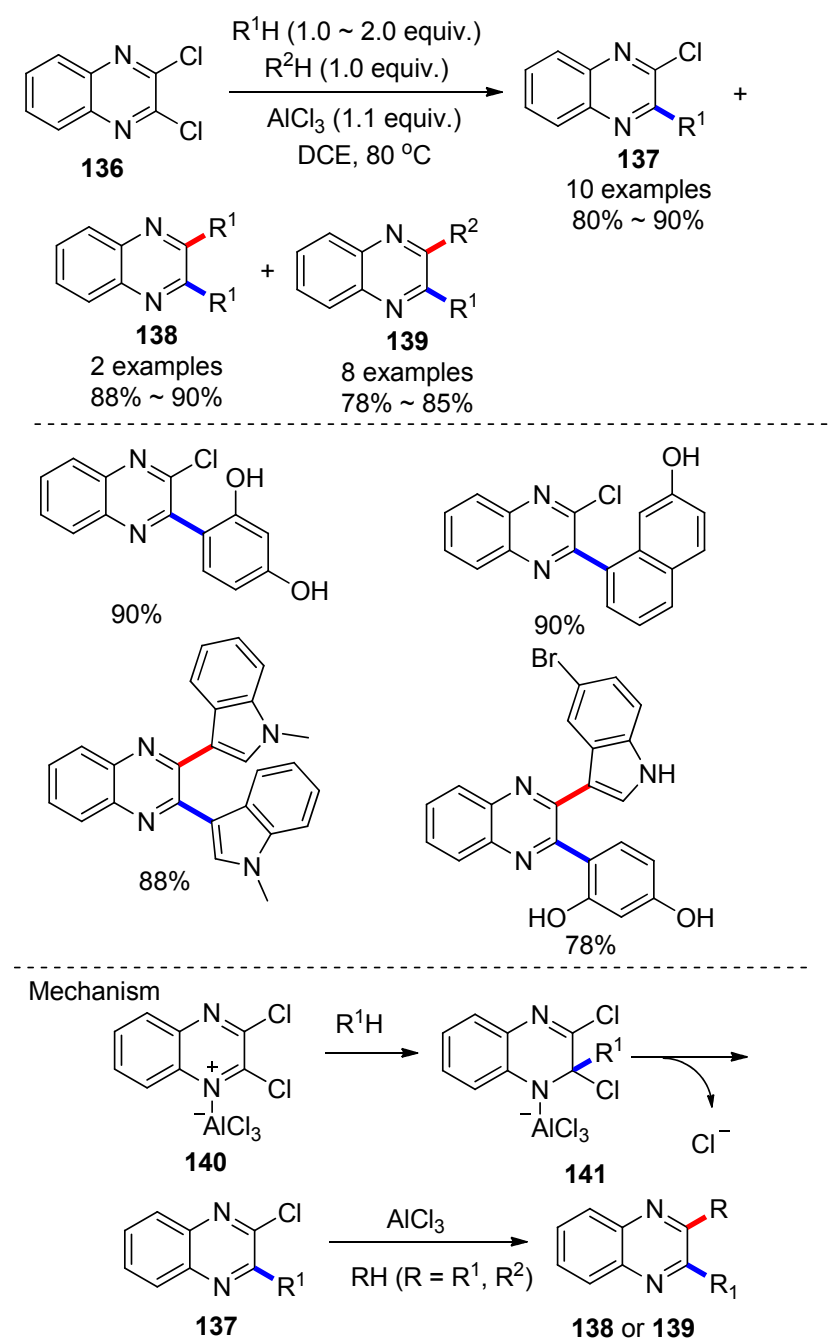

图式 $30 \mathrm{AlCl}_{3}$ 促进的 2,3-二取代喹喔啉的合成 Scheme 30 Synthesis of 2,3-disubstituted quinoxaline promoted by $\mathrm{AlCl}_{3}$

2013 年, 该课题组 ${ }^{[51]}$ 继续报道了 $\mathrm{AlCl}_{3}$ 促进的 2-氯 代-3-炔基-喹喔啉和芳烃之间的芳基化反应 (Scheme 31). 该方法为 2-(2,2-二芳基乙烯基)-3-芳基喹喔啉 144 的合成提供了一种直接的一步合成方法. 虽然该方法仅 适用于含有强供电子基的活性芳烃，但反应条件温和，
且反应时间较短. 此外, 该方法不需要使用昂贵的过渡 金属催化剂或有机金属试剂. 对于反应机理，他们认为 $\mathrm{AlCl}_{3}$ 与 2-氯代-3-炔基-喹喔啉的氮原子进行配位得到 中间体 145, 从而促进芳烃对炔基的亲核进攻，由此得 到的中间体 146 通过 $\mathrm{AlCl}_{3}$ 离去得到中间体 147, 最后通 过 $\mathrm{AlCl}_{3}$ 与第二个氮原子配位促进了芳烃对相邻碳的进 攻得到 2-(2,2-二芳基乙烯基)-3-芳基喹喔啉 144a.
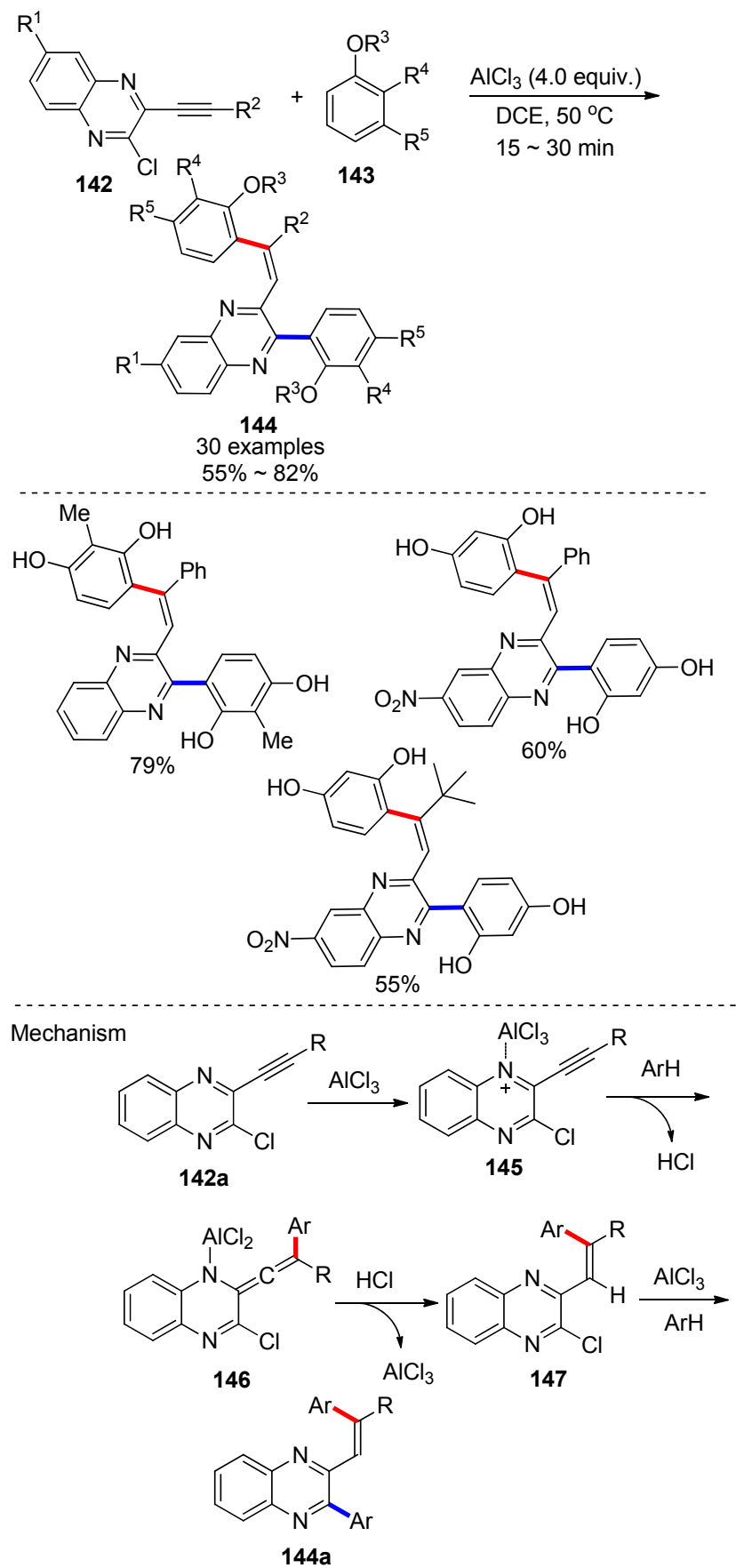

图式 $31 \mathrm{AlCl}_{3}$ 促进的 2-(2,2-二芳基乙烯基)-3-芳基喹喔啉的 合成

Scheme 31 Synthesis of 2-(2,2-diarylvinyl)-3-arylquinoxalines promoted by $\mathrm{AlCl}_{3}$ 


\section{$3.4 \mathrm{AlCl}_{3}$ 催化的插入反应}

2015 年, Kambe 课题组 ${ }^{[52]}$ 报道了 $\mathrm{AlCl}_{3}$ 催化异腈化 物插入次磺酰胺 148 的氮一硫键合成异硫腿 150 的反应 (Scheme 32). 在探究的一系列异腈底物中, 芳香族及茮 基异腈的反应效果最好, 最高可达 $93 \%$, 而对于脂肪族 异腈, 收率不佳. 由于 $\mathrm{AlCl}_{3}$ 催化的异腈化物插入次磺 酰胺类化合物的反应途径尚不清楚, 他们提出了一种可 能的机理: 次磺酰胺中的氮原子与 $\mathrm{AlCl}_{3}$ 配位得到配合 物 151, 从而激活 $\mathrm{N}-\mathrm{S}$ 键. 异腈基通过进攻 151 的硫原 子, 生成硫代异腈 152 与中间体 153, 两者进一步反应 生成异硫脲 150. 该方法为异硫脲的合成提供了一种简 便的方法.

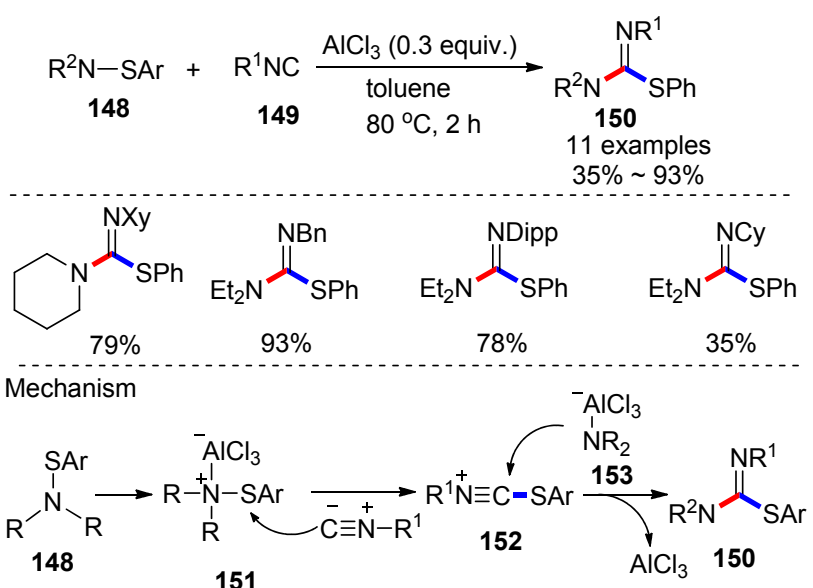

图式 $32 \mathrm{AlCl}_{3}$ 催化的异硫脲的合成

Scheme $32 \quad \mathrm{AlCl}_{3}$-catalyzed synthesis of isothioureas

\section{5 $\mathrm{AlCl}_{3}$ 促进的串联反应}

2019 年, Hachiya 课题组 ${ }^{[53]}$ 报道了 $\mathrm{AlCl}_{3}$ 促进连炔亚 胺与三甲基硅氧基烯的串联 1,4-加成反应和 1,6-加成反 应，合成了多种烯基亚胺基环丁烯酮 156 (Scheme 33). 对于反应机理，他们认为: 首先三甲基硅氧基烯的 $\beta$ 碳 与 $\mathrm{AlCl}_{3}$ 活化的连炔亚胺 157 发生 1,4-加成并经过分子 内环合得到中间体 158 , 从中间体 158 中脱去铝盐得到 炔基亚氨基环丁烯酮 159, 随后, 炔基亚氨基环丁烯酮 159 与三甲基硅氧基烯发生 1,6-加成反应并通过与水发 生质子化反应, 得到产物烯基亚氨基环丁烯酮 156. 值 得一提的是, 烯基亚胺基环丁烯酮可以通过热重排生成 顺式 $\beta$-内酰胺与反式 $\beta$-内酰胺.

\section{4 对硫的活化作用}

由于低价态的含硫基团(硫醚、硫醇、硫酚等)属于 软碱，因此三氯化铝对含硫基团的活化报道较少，能够 活化的含硫结构主要集中在硫羰基(如硫酰胺、硫氰酸 酯等)这一变形能力较差的结构.

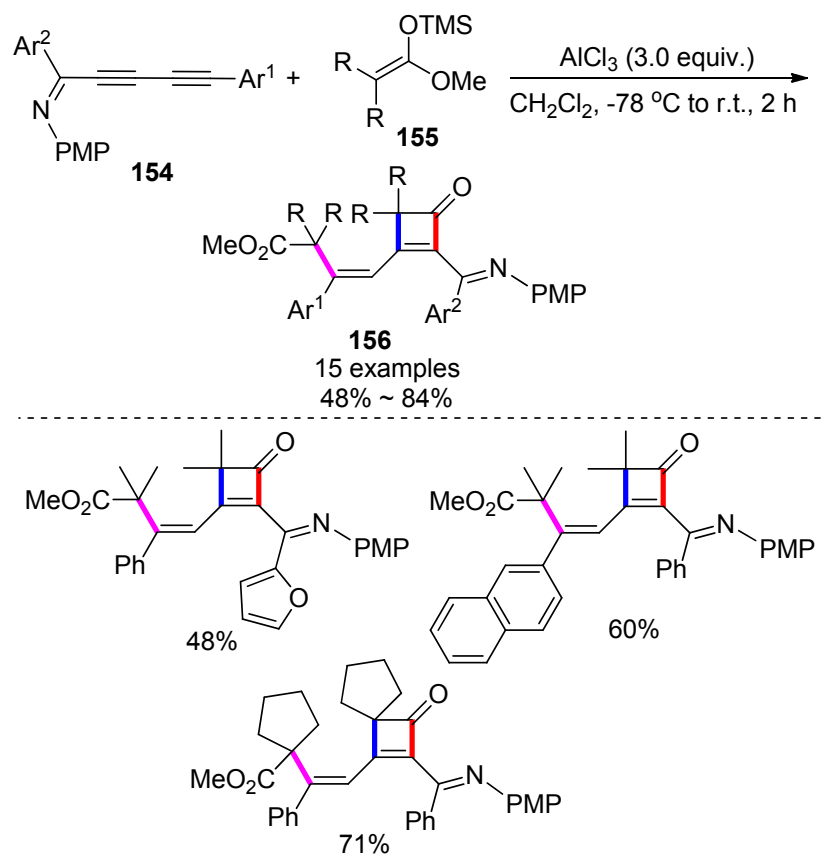

Mechanism
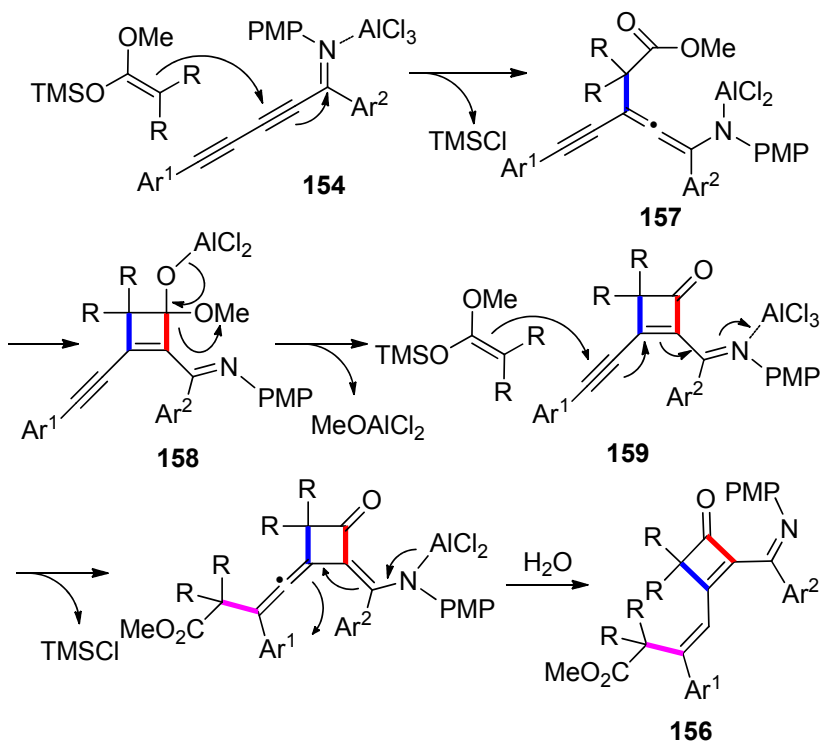

图式 $33 \mathrm{AlCl}_{3}$ 促进的烯基亚胺基环丁烯酮的合成

Scheme 33 Synthesis of alkenyl iminocyclobutenones promoted by $\mathrm{AlCl}_{3}$

\section{1 $\mathrm{AlCl}_{3}$ 促进的加成反应}

硫代酰胺与酰胺相比提高了刚性和稳定性, 可被用 作对水敏感的酰胺键的等位替代物. 并且硫代酰胺类化 合物在氮原子和硫原子处具有明显的亲核性 ${ }^{[54]}$, 可以 被用作合成具有重要意义的化合物骨架如苯并噻唑 ${ }^{[55]}$ 等的起始原料. 2016 年, Nair 课题组 ${ }^{[56]}$ 报道了以环己烷 为溶剂, 在 $\mathrm{AlCl}_{3}$ 促进下, 以芳基异硫氰酸酯和富电子 (异)芳香族化合物为原料, 进行傅克硫酰化反应 (Scheme 34). 在底物普适性研究时发现, 当异硫氰酸酯 上带有吸电子基时，产物收率更高，并且在与异芳烃反 
应时，与芳烃体系相比，反应速度更快，产物收率更高， 其中呋喃的收率比吡咯略高. 他们提出了一个合理的反 应机理: $\mathrm{AlCl}_{3}$ 与异硫氰酸芳基的硫原子配位生成络合 物 163, 从而增加了碳中心的亲电性, 使其受到富电子 (异)芳香族化合物的进攻, 产生的中间体 164 将失去质 子, 重新获得芳香性, 随后在水的参与下中间体 165 经 过异构化得到硫代酰胺 162a.
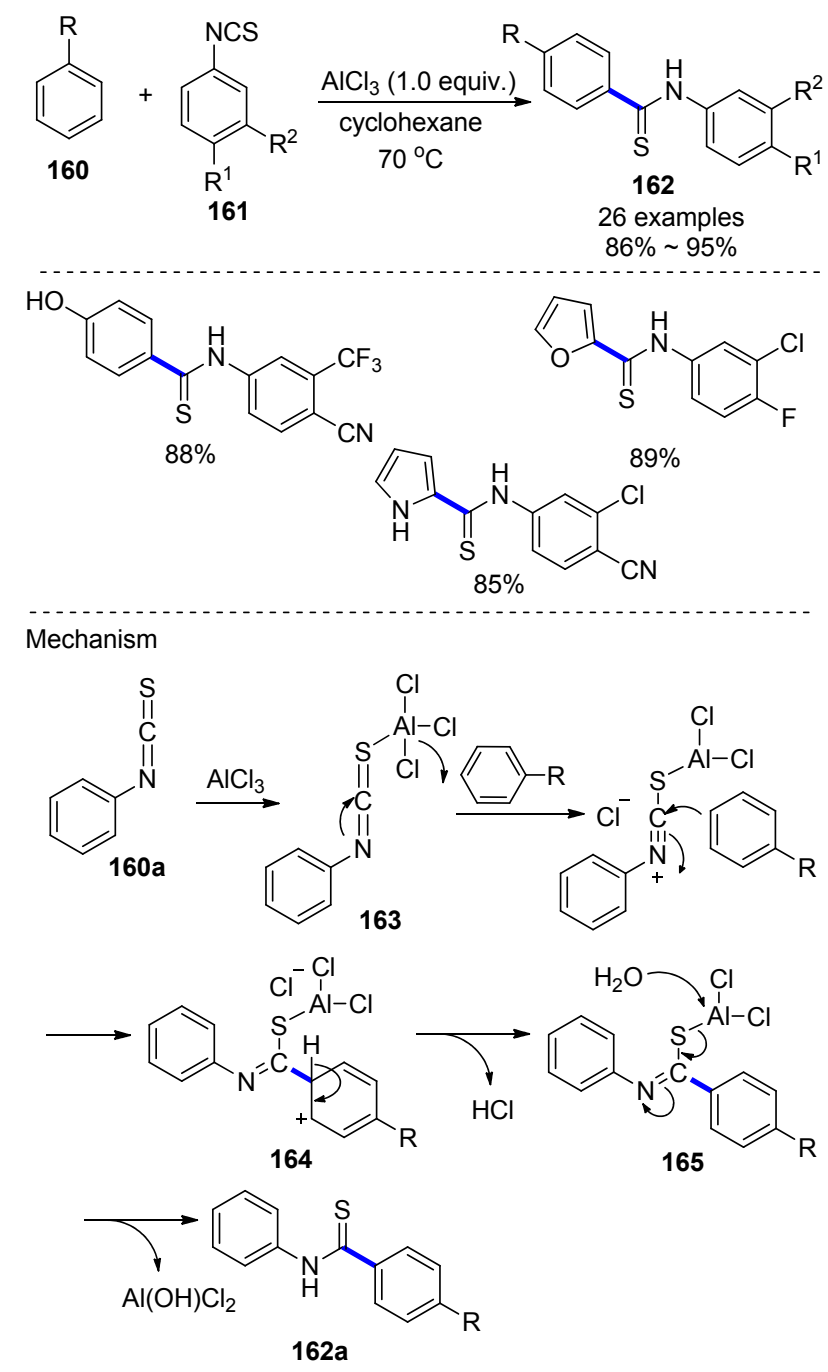

图式 $34 \mathrm{AlCl}_{3}$ 促进的硫代酰胺的合成

Scheme 34 Synthesis of thioamides promoted by $\mathrm{AlCl}_{3}$

\section{$4.2 \mathrm{AlCl}_{3}$ 催化的环化反应}

2018 年, 董志兵课题组 ${ }^{[57]}$ 报道了一种利用二甲基 二硫代氨基甲酸钠合成 2-颈基苯并噻唑、苯并啞唑及苯 并咪唑衍生物 168(或者 169)的方法(Scheme 35). 对于带 有不同电子性质取代基的氨基硫醇、氨基苯酚及二胺类 衍生物等双功能分子, 都可得到中等及良好的收率, 使 得该方法成为制备 2-颈基苯并杂环化合物的一种简便、 实用的方法. 他们推测反应通过 $\mathrm{AlCl}_{3}$ 与二甲基二硫代
氨基甲酸钠的硫羰基部分配位得到中间体 170, 增强了 其硫羰基碳接受电子的能力，随后双功能分子的氨基进 攻硫羰基，生成的二甲基苯基硫脲 171 通过分子内环化 反应并脱去二甲胺生成目标产物 168a. 当使用邻二胺 为底物时, 产物主要以环硫嫝 169 的形式存在.
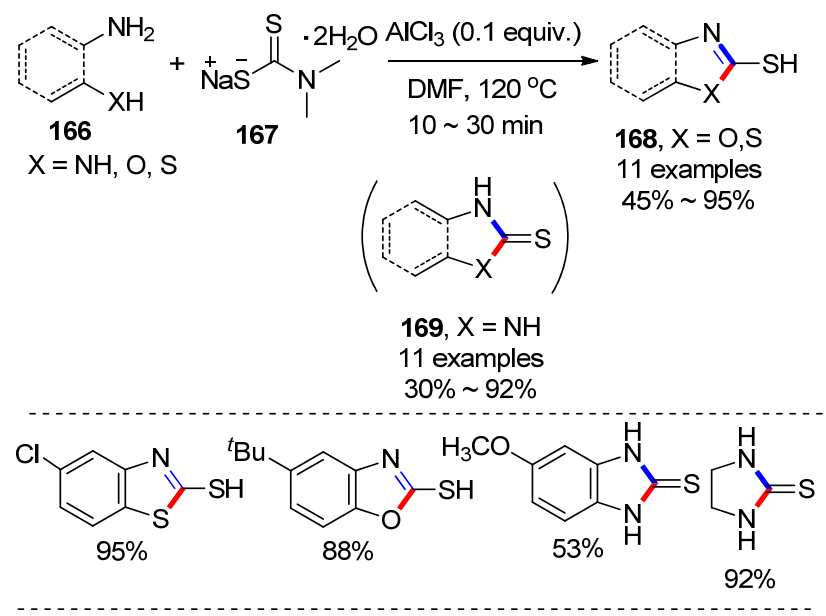

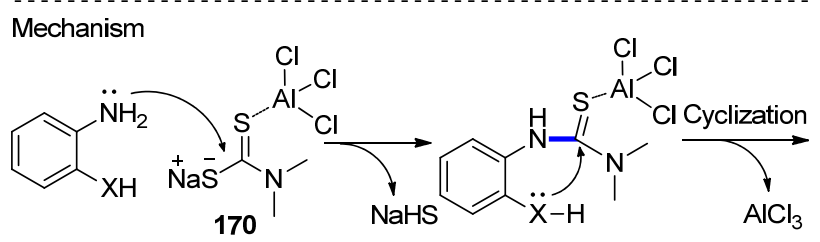<smiles>[Y]C(=S)Nc1ccccc1[X]</smiles>

图式 $35 \mathrm{AlCl}_{3}$ 催化的 2-颈基苯并杂环的合成 Scheme $35 \mathrm{AlCl}_{3}$-catalyzed synthesis of 2-mercapto benzoheterocycles

\section{5 对 $\pi$ 键的活化作用}

如上所述, $\mathrm{AlCl}_{3}$ 可通过与 $\mathrm{C}=\mathrm{Y}(\mathrm{Y}=\mathrm{O}, \mathrm{N}, \mathrm{S}$ 等)的 孤对电子形成配合物增强底物活性, 从而促进亲核试剂 对带正电荷的碳的亲核进攻. 可以将类似的概念推广到 碳碳不饱和键 ( $\pi$-电子), $\mathrm{AlCl}_{3}$ 可以选择性地激活碳碳双 键或参键, 从而诱导亲核试剂与双键或参键之间的反 应 $^{[58]}$.

硅氢化反应是一个不可缺少的方法来构建硅碳键, 大多数的方法涉及与单硅烷的反应，如氯二甲基硅烷、 苯基二甲基硅烷、三(三甲基硅基)硅烷等 ${ }^{[59]}$. 常用的含 铝催化剂有二氯乙基铝和三乙基铝等 ${ }^{[60]}$. 2010 年, Tanaka 课题组 ${ }^{[61]}$ 报道了 $\mathrm{AlCl}_{3}$ 催化的炔烃与五甲基二硅 烷的硅氢化反应(Scheme 36). 结果表明当使用分子内 参键的二取代炔烃时, 得到 $E$ 构型产物, 而使用端炔时 则得到 $Z$ 构型产物. 他们认为 $\mathrm{AlCl}_{3}$ 通过形成 $\pi$ 络合物 
175 激活炔烃, 硅烷上的氢负离子会从相反的方向进攻 缺电子的参键，由此生成的中间体 176 的乙烯基与五甲 基二硅烷阳离子之间发生偶联反应得到氢硅化产物

\section{$174 a$.}

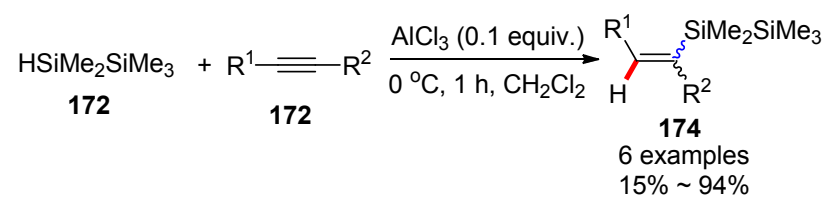
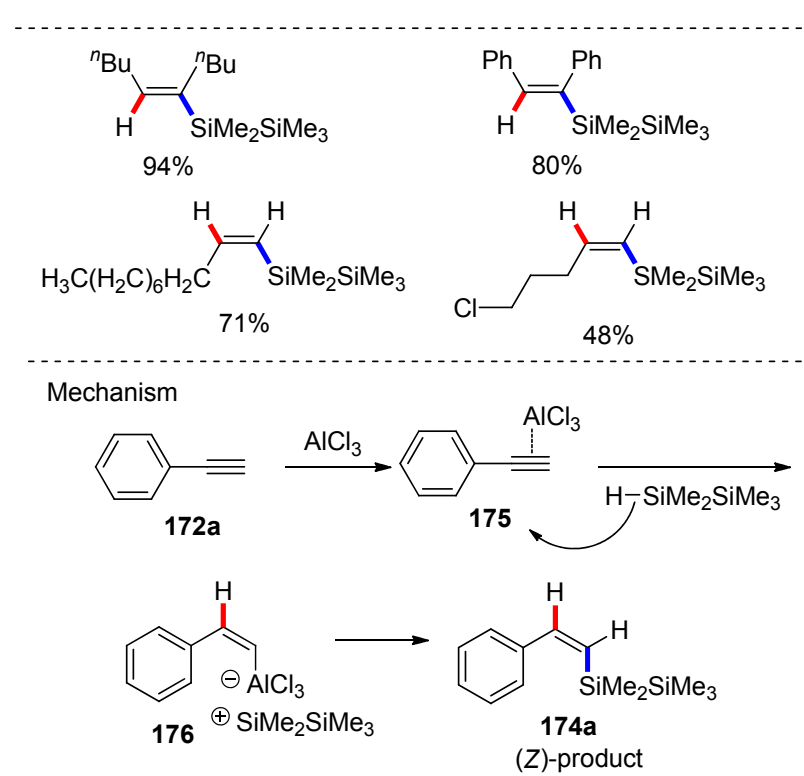

图式 $36 \mathrm{AlCl}_{3}$ 催化的炔烃的氢硅化反应

Scheme $36 \quad \mathrm{AlCl}_{3}$-catalyzed hydrosilylation of alkynes

\section{5 总结与展望}

总结了近 10 年来, 三氯化铝作为催化剂或促进剂 通过对含卤素、氧、氮、硫原子化合物及 $\pi$ 键的活化完 成的多种新型的有机转化, 并结合三氯化铝的结构对相 关的反应机制进行了解释和讨论. 鉴于三氯化铝廉价易 得、反应温和及活化位点多等特点, 这些反应或将在合 成相关的药物活性分子、中间体骨架以及材料分子中得 到广泛应用. 然而目前一些反应中三氯化铝用量远大于 底物用量, 催化效率方面有待提升. 并且三氯化铝促进 的某些转化机理并未得到相应实验证实, 许多新型反应 如 $\mathrm{AlCl}_{3}$ 与助催化剂与载体、离子液体共同使用也有待 化学家们的进一步探索和开发. 可以预见, 随着三氯化 铝应用方式的不断扩展, 以及三氯化铝与助催化剂共同 使用促进的催化性能改善, 必将推动三氯化铝应用领域 的不断发展.

\section{References}

[1] Chen, Z.; Qiu, X. L.; Yan, W.; Yang, H. N.; Ji, S. C.; Chen, M. H. Adv. Earth Sci. 2003, 18, 545 (in Chinese).

(陈忠, 丘学林, 颜文, 杨惠宁, 古森昌, 陈木宏, 地球科学进展, 2003, 18, 545.)
[2] Ashkenazi, D. Technol. Forecast. Soc. Change 2019, 143, 101.

[3] (a) Curtiss, L. A. Int. J. Quantum Chem. 1978, 14, 709.

(b) Bigelow, M. J. J. Chem. Educ. 1969, 46, 495.

(c) Aarset, K.; Shen, Q.; Thomassen, H.; Richardson, A. D.; Hedberg, K. J. Phys. Chem. A 1999, 103, 1644.

[4] Pearson, R. G. J. Am. Chem. Soc. 1963, 85, 3533.

[5] Yamamoto, Y. J. Org. Chem. 2007, 72, 7817.

[6] Zhao, Y.; Yang, Z.; Tang, L. Chin. J. Org. Chem. 2003, 23, 1219 (in Chinese).

(赵䒯，杨志，汤林，有机化学, 2003, 23, 1219.)

[7] Kürti, L.; Czakó, B. Strategic Applications of Named Reactions in Organic Synthesis, Elsevier Academic Press, San Diego, CA, 2005.

[8] Chong, H. S.; Chen, Y. W. Org. Lett. 2013, 15, 5912.

[9] Rossiter, B. E.; Swingle, N. M. Chem. Rev. 1992, 92, 771.

[10] Swaminathan, S.; Narayanan, K. V. Chem. Rev. 1971, 71, 429

[11] Beak, P.; Berger, K. R. J. Am. Chem. Soc. 1980, 102, 3848.

[12] Shono, T.; Nishiguchi, I.; Sasaki, M.; Ikeda, H.; Kurita, M. J. Org. Chem. 1983, 48, 2503.

[13] Hoffmann, H. M. R.; Tsushima, T. J. Am. Chem. Soc. 1977, 99 6008 .

[14] Tanaka, S.; Kunisawa, T.; Yoshii, Y.; Hattori, T. Org. Lett. 2019, 21, 8509.

[15] Koo, H.; Kim, H. Y.; Oh, K. Org. Chem. Front. 2019, 6, 1868

[16] Xu, S. B.; Li, C. J.; Jia, X. S.; Li, J. J. Org. Chem. 2014, 79, 11161.

[17] Devi, N. S.; Singh, S. J.; Devi, L. R.; Singh, O. M. Tetrahedron Lett. 2013, 54, 183.

[18] Chen, L.; Teng, W.; Geng, X. L.; Zhu, Y. F.; Guan, Y. H.; Fan, X. H. Appl. Organomet. Chem. 2017, 31, 3863.

[19] Xu, X. M.; Lei, C. H.; Tong, S.; Zhu, J. P.; Wang, M. X. Org. Chem. Front. 2018, 5, 3138

[20] Aleksić, M.; Bertoša, B.; Nhili, R.; Uzelac, L.; Jarak, I.; Depauw, S.; David-Cordonnier, M. H.; Kralj, M.; Tomić, S.; Karminski-Zamola, G. J. Med. Chem. 2012, 55, 5044

[21] Dénès, F.; Pichowicz, M.; Povie, G.; Renaud, P. Chem. Rev. 2014, 114, 2587.

[22] Paul, S.; Shrestha, R.; Edison, T. N. J. I.; Lee, Y. R.; Kim, S. H. Adv. Synth. Catal. 2016, 358, 3050

[23] Wang, Z.; Xue, L.; He, Y.; Weng, L.; Fang, L. J. Org. Chem. 2014 $79,9628$.

[24] Gao, W. C.; Liu, T.; Cheng, Y. F.; Chang, H. H.; Li, X.; Zhou, R.; Wei, W. L.; Qiao, Y. J. Org. Chem. 2017, 82, 13459.

[25] Gao, W. C.; Cheng, Y. F.; Chang, H. H.; Li, X.; Wei, W. L.; Yang, P. J. Org. Chem. 2019, 84, 4312.

[26] Yu, X. Z.; Shang, Y. Z.; Cheng, Y. F.; Tian, J.; Niu, Y.; Gao, W. C. Org. Biomol. Chem. 2020, 18, 1806.

[27] Zhang, L.; Li, X. J.; Wang, Z. W.; Zhao, J. W.; Wang, J. J.; Han, J. W.; Zhu, S. Z. Tetrahedron 2013, 69, 7975.

[28] Wang, X. N.; Krenske, E. H.; Johnston, R. C.; Houk, K. N.; Hsung, R. P. J. Am. Chem. Soc. 2015, 137, 5596

[29] Zhu,Y. Y.; Zhang, M. L.; Li, T.; Song, X. X. ChemistrySelect 2019 , 4, 10838 .

[30] Cao, D. P.; Zhang, K. P.; An, R.; Xu, H.; Hao, S.; Yang, X. G.; Hou, Z.; Guo, C. Org. Lett. 2019, 21, 8948

[31] Tskhovrebov, A. G.; Naested, L. C. E.; Solari, E.; Scopelliti, R.; Severin, K. Angew. Chem., Int. Ed. 2015, 54, 1289.

[32] Zhu, Z. Q.; Bao, P.; Wang, T. T.; Huang, Z. Z. Chin. J. Chem. 2014, $32,1176$.

[33] (a) Zhou, J. H.; Jiang, B.; Meng, F. F.; Xu, Y. H.; Loh, T. P. Org. Lett. 2015, 17, 4432.

(b) Yepes, D.; Pérez, P.; Jaquea, P.; Fernández, I. Org. Chem. Front. 2017, 4, 1390.

[34] Masson, G; Lalli, C.; Benohoud, M.; Dagousset, G. Chem. Soc. Rev. 2013, 42,902 .

[35] Jian, W. J.; Qian, B.; Bao, H. L.; Li, D. L. Tetrahedron 2017, 73, 4039.

[36] Yang, G.; Shen, Y.; Li, K.; Sun, Y.; Hua, Y. J. Org. Chem. 2011, 76, 229.

[37] Yang, G.; Sun, Y.; Shen, Y.; Chai, Z.; Zhou, S.; Chu, J.; Chai, J. J. 
Org. Chem. 2013, 78, 5393.

[38] Shen, Y.; Chai, J.; Yang, G.; Chen, W.; Chai, Z. J. Org. Chem. 2018, $83,12549$.

[39] Yang, G.; Wang, T.; Chai, J.; Chai, Z. Eur. J. Org. Chem. 2015, 2015,1040

[40] Augustin, A. U.; Sensse, M.; Jones, P. G.; Werz, D. B. Angew. Chem., Int. Ed. 2017, 56, 14293.

[41] Ge, J. J.; Yao, C. Z.; Wang, M. M.; Zheng, H. X.; Kang, Y. B.; Li, Y. D. Org. Lett. 2016, 18, 228.

[42] Wang, Z.; Yuan, Z. H.; Han, X. Y.; Weng, Z. Q. Adv. Synth. Catal. 2018, 360, 2078.

[43] (a) Beck, B.; Magnin-Lachaux, M. Herdtweck, E.; Dömling, A. Org. Lett. 2001, 3, 2875.

(b) Kaim, L. E.; Gizolme, M.; Grimaud, L. Org. Lett. 2006, 8, 5021.

[44] Lyu, L. Y.; Xie, H.; Mu, H. X.; He, Q. J.; Bian, Z. X.; Wang, J. Org. Chem. Front. 2015, 2, 815.

[45] Hu, Q. Q.; Liu, Y.; Deng, X. C.; Li, Y. J.; Chen, Y. F. Adv. Synth. Catal. 2016, 358, 1689.

[46] Dimitrov, P.; Emert, J.; Faust, R. Macromolecules 2012, 45, 3318.

[47] Chen, J.; Mao, J.-C.; He, Y.; Shi, D. Q.; Zou, B. Y.; Zhang, G. Q. Tetrahedron 2015, 71, 9496

[48] Zhai, J. J.; Yao, Z. G.; Xu, F. Chin. J. Org. Chem. 2014, 34, 1639 (in Chinese).
(翟娇娇, 姚志刚, 徐凡, 有机化学, 2014, 34, 1639.)

[49] Liu, G. Q.; Cui, B.; Xu, R.; Li, Y. M. J. Org. Chem. 2016, 81, 5144.

[50] Kumar, K. S.; Meesa, S. R.; Rajeshama, B.; Bhaskera, B.; Ashfaq, M. A.; Khan, A. A.; Rao, S. S.; Pal, M. Bioorg. Med. Chem. 2012, 20, 1711.

[51] Nakhi, A.; Archana, S.; Seerapu, G. P. K.; Chennubhotla, K. S.; Kumar, K. L.; Kulkarni, P.; Haldar, D.; Pal, M. Chem. Commun. 2013, 49, 6268.

[52] Shiro, D.; Fujiwara, S.; Tsuda, S.; Iwasaki, T.; Kuniyasu, H.; Kambe, N. Tetrahedron Lett. 2015, 56, 1531.

[53] Hachiya, I.; Nakamura, K.; Hara, M.; Sato, K.; Shimizu, M. J. Org. Chem. 2019, 84, 14770.

[54] Tadeusz. S.; Jagodziski, T. S. Chem. Rev. 2003, 103, 197.

[55] Alla, S. K.; Sadhu, P.; Punniyamurthy, T. J. Org. Chem. 2014, 79, 7502.

[56] Kumar, K.; Konar, D.; Goyal, S.; Gangar, M.; Chouhan, M.; Rawal, R. K.; Nair, V. A. ChemistrySelect 2016, 1, 3228.

[57] Liu, X.; Zhang, S. B.; Dong, Z. B. Eur. J. Org. Chem. 2018, 39, 5406.

[58] Yamamoto, Y. J. Org. Chem. 2007, 72, 7817.

[59] Takaya, J.; Iwasawa, N. J. Am. Chem. Soc. 2017, 139, 6074.

[60] Nikonov, G. I. ACS Catal. 2017, 7, 7257.

[61] Kato, N.; Tamura, Y.; Kashiwabara, T.; Sanji, T.; Tanaka, M. Organometallics 2010, 29, 5274.

(Zhao, C.) 